\title{
Salivary Gland Pathologies
}

\author{
Nisheet Anant Agni
}

\subsection{Introduction}

The salivary glands secrete saliva which has lubricating, immunologic, digestive, and cleansing functions. They are affected by systemic and local inflammatory conditions, obstructive pathologies, as well as neoplasms. Most of the tumors are parenchymal in origin, whereas few could be interstitial. Majority of tumors affecting major glands are benign, but those affecting minor salivary glands are more often than not, malignant. The disorders that involve these glands can either be acute or chronic inflammatory lesions, congenital abnormalities, systemic disorders, or benign and malignant tumors. However the most, common disorders affecting salivary glands are tumors and infections.

\subsection{Surgical Anatomy}

\subsubsection{Parotid Gland}

The gland lies in the retromandibular fossa bound medially by the styloid process and superiorly by external acoustic meatus and mastoid process, and it touches the medial pterygoid muscle and mandibular ramus (Fig. 46.1). A part of the gland may also cover the TMJ in front of the ear but never extends beyond the zygomatic arch. The parotid capsule is a dense, adherent fibrous condensation of deep cervical fascia which is tough and unyielding. Hence parotid space infections show minimal swelling but are severely painful. Incision and drainage is needed early on, without a frank fluctuant abscess to relieve the pressure within the capsule to

Electronic Supplementary Material The online version of this chapter (https://doi.org/10.1007/978-981-15-1346-6_46) contains supplementary material, which is available to authorized users.

N. A. Agni $(\bowtie)$

Department of Oral and Maxillofacial Surgery, SMBT Institute of

Dental Sciences and Research, Nashik, India prevent pressure necrosis of the parenchyma. Due to weakness in the capsule covering the deep surface of the gland, parotid abscess may spread into the lateral pharyngeal space, if not drained promptly [1]. Benign tumors grow slowly and hence take a longer time to manifest as external bulges. Parotid gland has a superficial lobe $(80 \%)$ and a deep lobe (20\%) connected by an isthmus with the facial nerve passing between the two lobes.

The facial nerve is related to the parotid gland in a number of ways [2].

1. (a) Superficial and deep lobes are united above, so that the gland is essentially folded over the nerve.

(b) An isthmus uniting the two lobes.

(c) Combination of (a) and (b)

2. The gland and nerve can also lie intertwined within superficial and deep lobes; relation will vary according to plane of section.

The intratemporal and intraparotid facial nerve has varied pattern of branching which is of immense surgical importance and might show bifurcation and trifurcation of the main trunk within the mastoid segment (Fig. 46.2). This intratemporal division of the facial nerve is associated with congenital abnormalities of the pinna or inner ear (Table 46.1).

Parotid duct or the Stensen's duct crosses the masseter about a finger breadth below the zygomatic arch. It then takes a sharp turn medially at the anterior border of the masseter further traversing through the buccal fat pad and buccinator muscle. It then runs obliquely between the buccinator and oral mucosa to open on the parotid papilla, opposite the second maxillary molar. The obliquity of the duct in between the buccinator and mucosa acts like a valve to prevent inflation of the duct while blowing air. The duct lies between the upper and lower buccal branches of the facial nerve. Its caliber is about $3 \mathrm{~mm}$, but at the point where it penetrates the buccinator muscle, an isthmus narrows down the duct to $1.2 \mathrm{~mm}$, and at the orifice (ostium), it is $0.5 \mathrm{~mm}$. 
Fig. 46.1 Transverse section of parotid gland

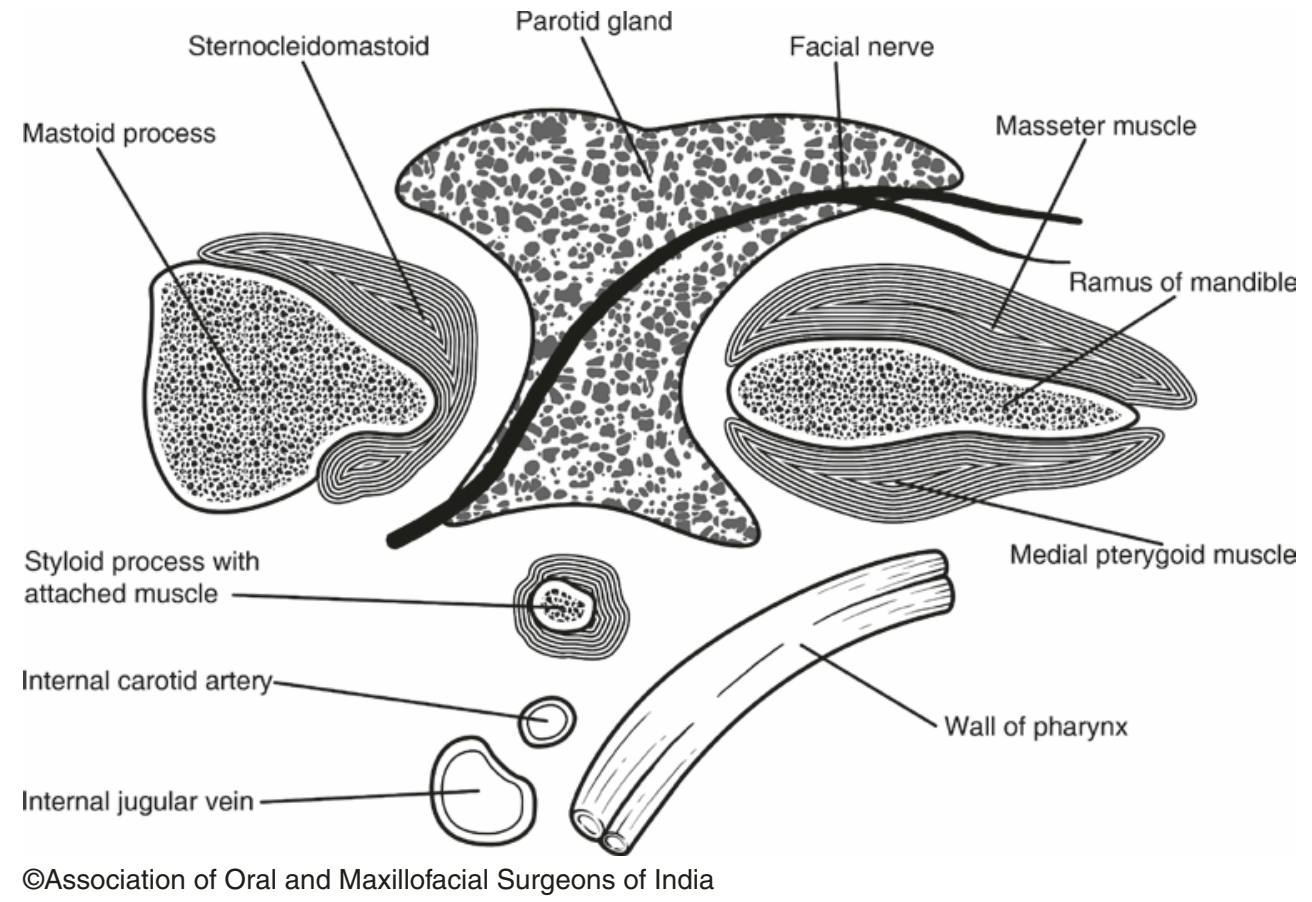

Structures traversing the parotid gland from lateral to medial (superficial to deep) include the facial nerve, retromandibular vein, and external carotid artery. Few parotid lymph nodes are also present within the gland.

Parasympathetic secretomotor fibers from the inferior salivary nucleus of the ninth cranial nerve supply the gland. Nerve fibers pass to the otic ganglion via the tympanic branch of the glossopharyngeal nerve and the lesser petrosal nerve. Postganglionic parasympathetic fibers reach the parotid gland via the auriculotemporal nerve, which lies in contact with the deep surface of the gland. Postganglionic sympathetic fibers reach the gland as a plexus of nerves around the external carotid artery [4].

\subsubsection{Identification of the Facial Nerve $[5,6]$}

The facial nerve identification can be done either proximally or distally. Proximally the main trunk of the nerve is identified before it enters the gland. Distally it is identified as branches after the nerve leaves the gland (Table 46.2).

There are four facial nerve pointers at the stylomastoid foramen. However more techniques have been added later on by various authors. They are as follows:

1. The cartilaginous pointer of Conley (1978) is created at its anterior inferior border and is the least reliable one. The backward pull on the cartilage causes the meatus to assume the shape of a horn, the curved extremity of which allegedly points to the position of the facial nerve. The nerve is located medial and inferior to the pointer (Fig. 46.3).
2. A short segment of the facial nerve lies in between the stylomastoid foramen and parotid gland and is an ideal location to identify it. It can be located in the tympanomastoid sulcus which is formed by the edge of the bony external meatus and anterior face of the mastoid process. The nerve emerges from the stylomastoid foramen some 3-4 mm deep to the outer edge of the bony external canal. The tympanomastoid sulcus is filled with fibrofatty lobules that mimic the facial nerve trunk which may lie as deep as $1 \mathrm{~cm}$ to this landmark.

3. The anterior superior aspect of the posterior belly of the digastric muscle is inserted just behind the stylomastoid foramen. The posterior belly of the digastric muscle lies just inferior to the nerve and is the most reliable landmark to identify the nerve (Fig. 46.4).

4. The styloid process is a confirmatory landmark. The facial nerve lies lateral to the styloid process near the styloid base. The posterior auricular artery bleeds frequently while looking for the facial nerve since it lies below and just lateral to the nerve, and hence it cannot be relied upon for identification of the nerve.

5. Borle's triangle has been recently introduced to locate the facial nerve trunk. Lines are drawn from the tip of the mastoid process, running along the superior border of the posterior belly of digastric muscle and posterior border of the ramus of the mandible. These two lines intersect with each other anteriorly, forming the apex of the triangle (angle a). The base of the triangle is marked by drawing the third line starting from the tip of the mastoid process (angle b), running anteriorly till it joins 
Fig. 46.2 (a)-(i) Katz-

Catalano classification based on operative findings

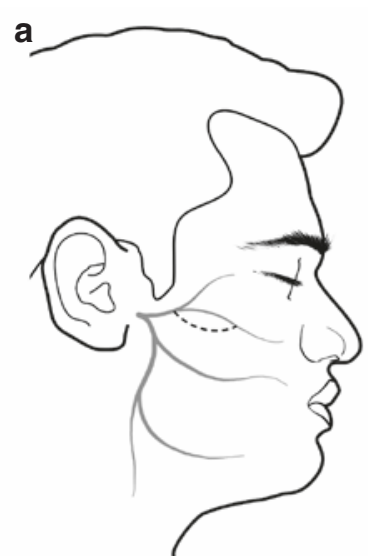

d

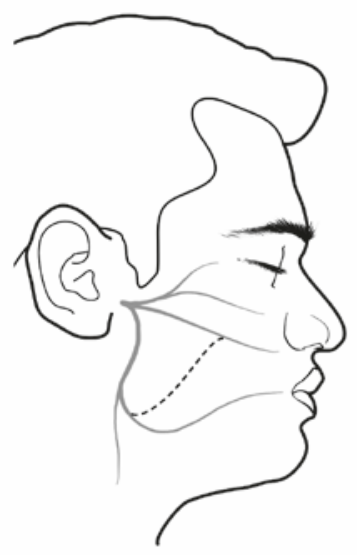

g

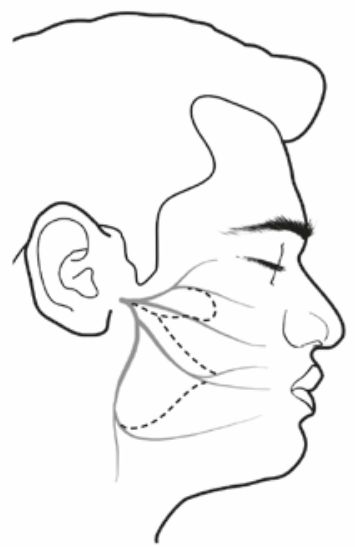

b

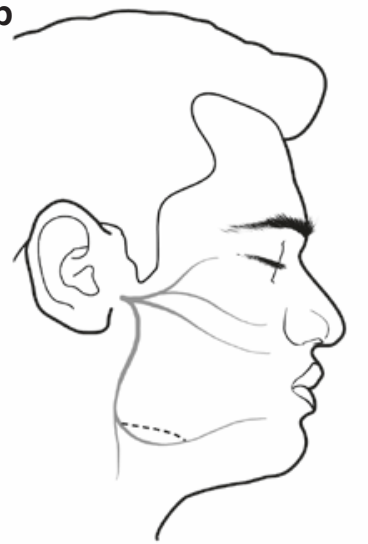

e

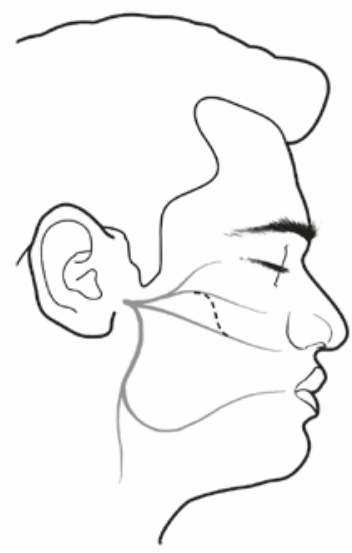

h

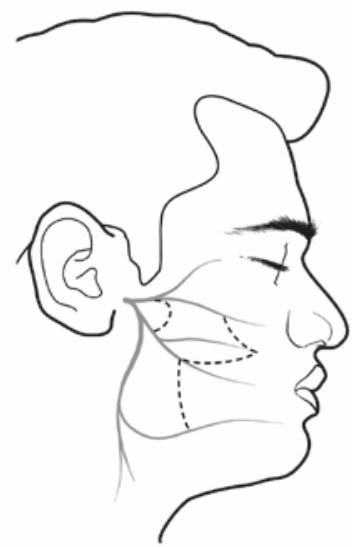

C

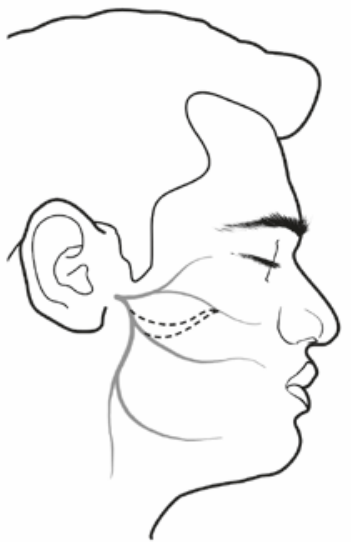

f

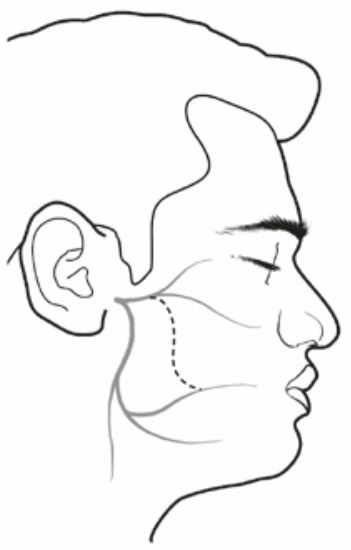

i

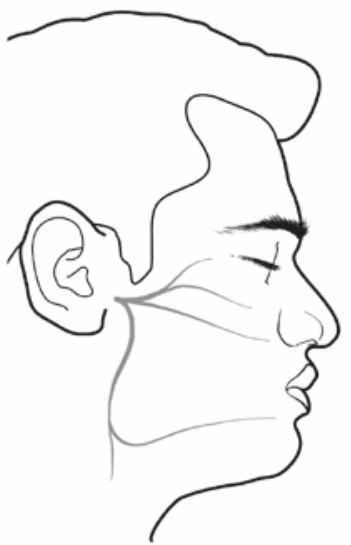

CAssociation of Oral and Maxillofacial Surgeons of India

Table 46.1 Katz-Catalano classification

\begin{tabular}{l|l|l} 
Type 1 & $25 \%$ & Branches are separate
\end{tabular}

Type 2 14\% Buccal branch fuses with zygomatic branch

Type $344 \%$ Major communicating, buccal, and other branches

Type $4 \quad 14 \%$ Complex branching between all branches

Type 5 $3 \%$ More than one major trunk

Katz and Catalano [3], 1987
Table 46.2 Facial nerve identification

Anterograde approach-Direct identification of main trunk at

1 stylomastoid foramen

2 Retrograde approach-Early identification of mandibular branch over posterior facial vein or other branches along the parotid duct

3 Supravital staining of parotid-gland is stained blue, tumor is unstained, and facial nerve is gleaming white 


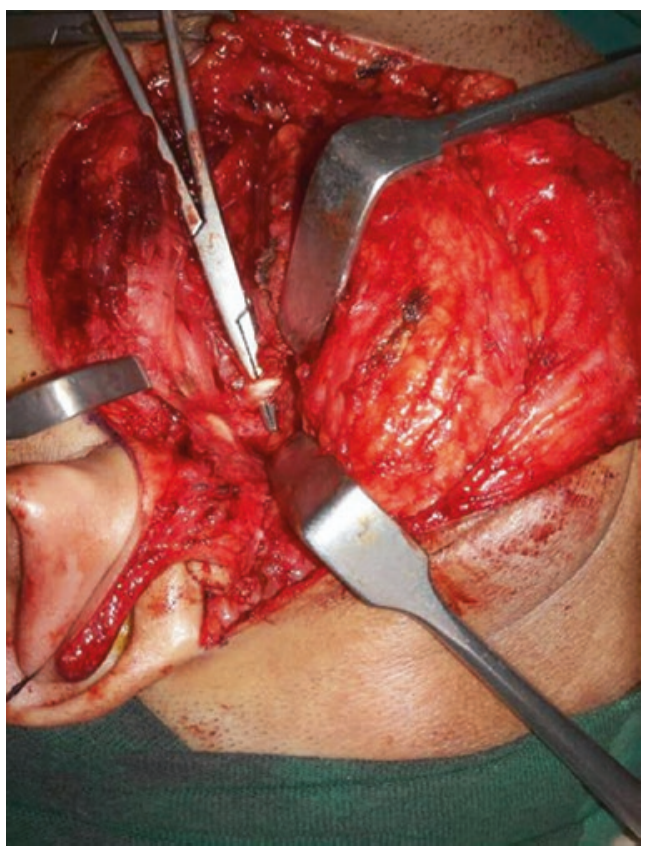

CAssociation of Oral and Maxillofacial Surgeons of India

Fig. 46.3 Showing relation of cartilaginous pointer and facial nerve main trunk

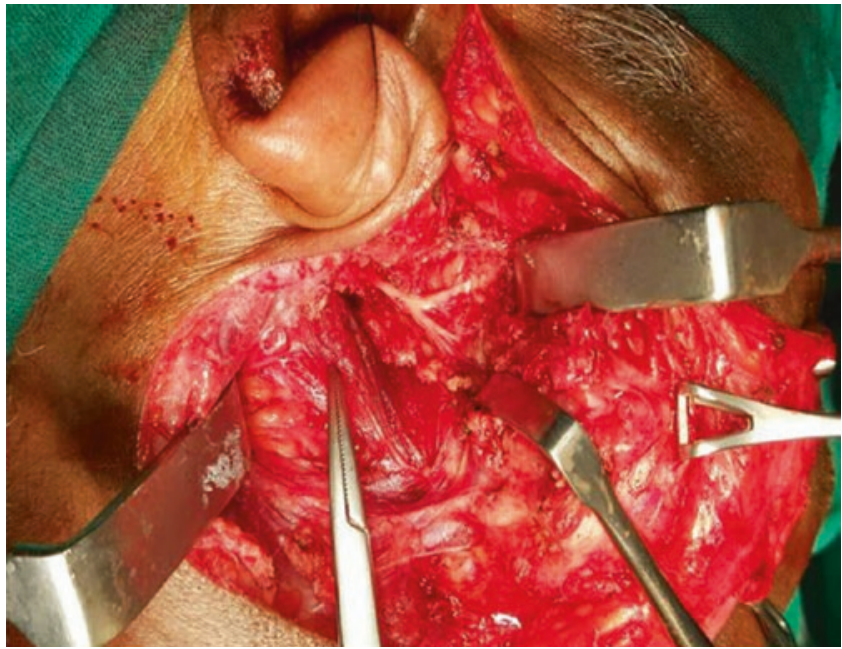

CAssociation of Oral and Maxillofacial Surgeons of India

Fig. 46.4 Showing relation of the posterior belly of the digastric muscle and main trunk of the facial nerve (muscle pointed by mosquito forceps)

the second drawn line along the posterior border of the ramus (angle c). The facial nerve trunk is often found within this triangle just above the angle $b$ formed by the first and the third line if gentle and blunt dissection is carried out at this point. The mean distance of nerve trunk from the angle $b$ is $12.18 \pm 2 \mathrm{~mm}$ within a range of 9-15 mm [7] [Fig. 46.5-https://www.ncbi.nlm.nih. gov/pmc/articles/PMC6126203/. doi: https://doi. org/10.1016/j.jobcr.2018.08.004. (open access)].

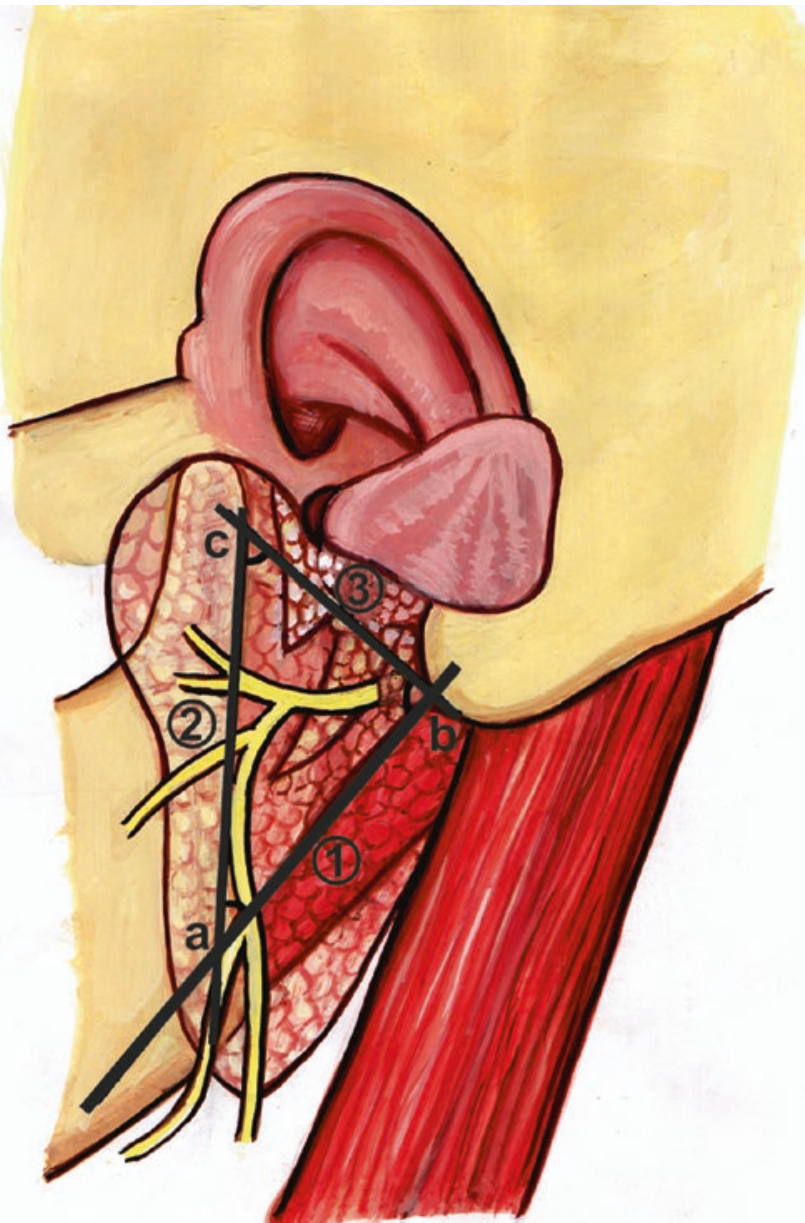

Fig. 46.5 Borle's triangle. Line 1: Started from mastoid process tip and running along the superior border of posterior belly of the digastric muscle. Line 2: At the posterior border of ramus of the mandible. Line 3: Starts from the tip of the mastoid process running anteriorly till it joins the second line. Angle a: Lines 1 and 2 intersect with each other forming the apex of triangle. Angle b: Is the base of the triangle. Angle $c:$ Is the angle where third line meets second line

When identification of facial nerve trunk is difficult using the above said pointers due to distorted anatomy due to the tumor, a retrograde approach can be used by identifying a peripheral branch of the nerve and tracing it proximally. The easiest branch to locate is the marginal mandibular nerve. Baker et al. have reported that the marginal mandibular nerve is located 1-2 $\mathrm{cm}$ below the inferior border of the mandible. The marginal mandibular branch can be used to trace the facial nerve in a retrograde direction by identifying it at the point of emergence of the retromandibular vein and then carrying out a proximal dissection. By working backward along the nerve, the two divisions, the other branches, and the main trunk can be found [8].

Figure 46.6 represents the average distance of facial nerve pointers from the surrounding landmarks (Table 46.3).

Intraoperative facial nerve monitoring using electromyographic techniques can also be used for identification of the main branch or the peripheral branches in centripetal or retrograde approach. In pediatric population the facial nerve trunk 
Fig. 46.6 Distance from facial nerve pointers

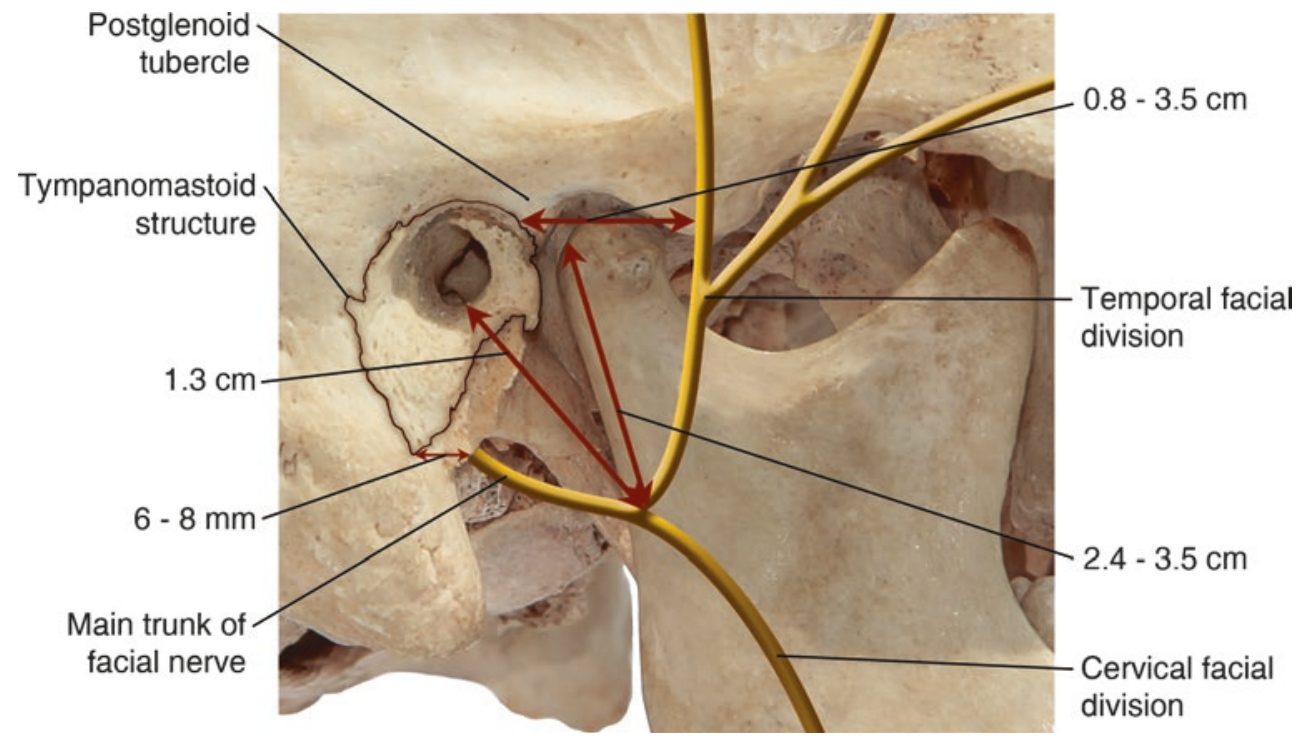

(CAssociation of Oral and Maxillofacial Surgeons of India
Table 46.3 Distance of the facial nerve pointers from the surrounding landmarks [10]

\begin{tabular}{|l|l|r|l|}
\hline $\begin{array}{l}\text { Sr. } \\
\text { no. }\end{array}$ & Pointer & $\begin{array}{l}\text { Distance in } \\
\mathrm{mm}\end{array}$ & $\begin{array}{l}\text { Mean in } \\
\mathrm{mm}\end{array}$ \\
\hline 1 & Tragal pointer & $24.3-49.2$ & \multicolumn{1}{l|}{34} \\
\hline 2 & $\begin{array}{l}\text { Posterior belly of the digastric } \\
\text { muscle }\end{array}$ & $9.7-24.3$ & 14.6 \\
\hline 3 & External auditory canal & $7.3-21.9$ & 13.4 \\
\hline 4 & Tympanomastoid suture & $4.9-18.6$ & 10.0 \\
\hline 5 & Styloid process & $4.3-18.6$ & 9.7 \\
\hline 6 & Transverse process of axis & $9.7-36.8$ & 16.9 \\
\hline 7 & Angle of the mandible & $25.3-48.69$ & 38.1 \\
\hline & & & \\
\hline
\end{tabular}

exits the stylomastoid foramen and is found approximately $1 \mathrm{~cm}$ anterior to mastoid process and $1.5 \mathrm{~cm}$ posterior to the ramus of the mandible. The parotid does not extend posterior to the ramus of the mandible in the newborn infant and consequently covers only the lower distal branches of the nerve [9].

\subsubsection{Facial Nerve Monitoring}

There are two types of facial nerve monitoring:

- Electromyography

- Pressure or strain gauge sensor

Facial nerve monitoring is performed with a nerve stimulator which can either be monopolar or bipolar. The monopolar stimulator is more useful for identifying the nerve, while the bipolar is more useful if the nerve course is evident. However, a bipolar stimulator is more precise.

\subsubsection{Submandibular Glands}

It is a U-shaped gland with a smaller deep lobe and larger superficial lobe enveloping the mylohyoid muscle. Hence during surgical removal, the mylohyoid has to be retracted anteriorly to expose the deep lobe and the Wharton's duct. The capsule is loosely attached to the gland substance, and hence the gland can be shelled out easily.

Since the submandibular group of lymph nodes are in contact with the gland or embedded in it, it is essential to clear the nodes along with the gland during a neck dissection.

The facial artery loops around the submandibular gland. The facial artery is visualized by retracting the posterior belly of the digastric muscle inferiorly. Hence, during excision of the submandibular gland, the facial artery and vein were customarily ligated. However, during neck dissection, the current standard is to try and save it so that it can be used for anastomosis during a free flap reconstruction.

The facial artery is ligated away from the external carotid artery, so that in case the vessel retracts into the tissue, it can be located and religated and bleeding can be controlled. In case the ligature slips and the facial artery retracts, the posterior belly of the digastric muscle is divided for easy location of the bleeding vessel.

The lingual nerve passes below the duct and forms a loop around its outer aspect before inserting into the tongue mucosa. It is at risk when the deep part of the gland is being mobilized. The submandibular duct or Warton's duct is longer and has a tortous, uphill course. Thus the secretions have to be emptied against gravity, and there are increased chances of retention. Also, the mineral content of the secretion is high, especially calcium content which along with increased retention of secretions results into higher incidence of calculus formation and inflammatory pathologies in the submandibular gland and duct.

Figure $46.7 \mathrm{a}, \mathrm{b}$ shows the relations of the submandibular gland. 
Fig. 46.7 (a, b) Relations of submandibular gland

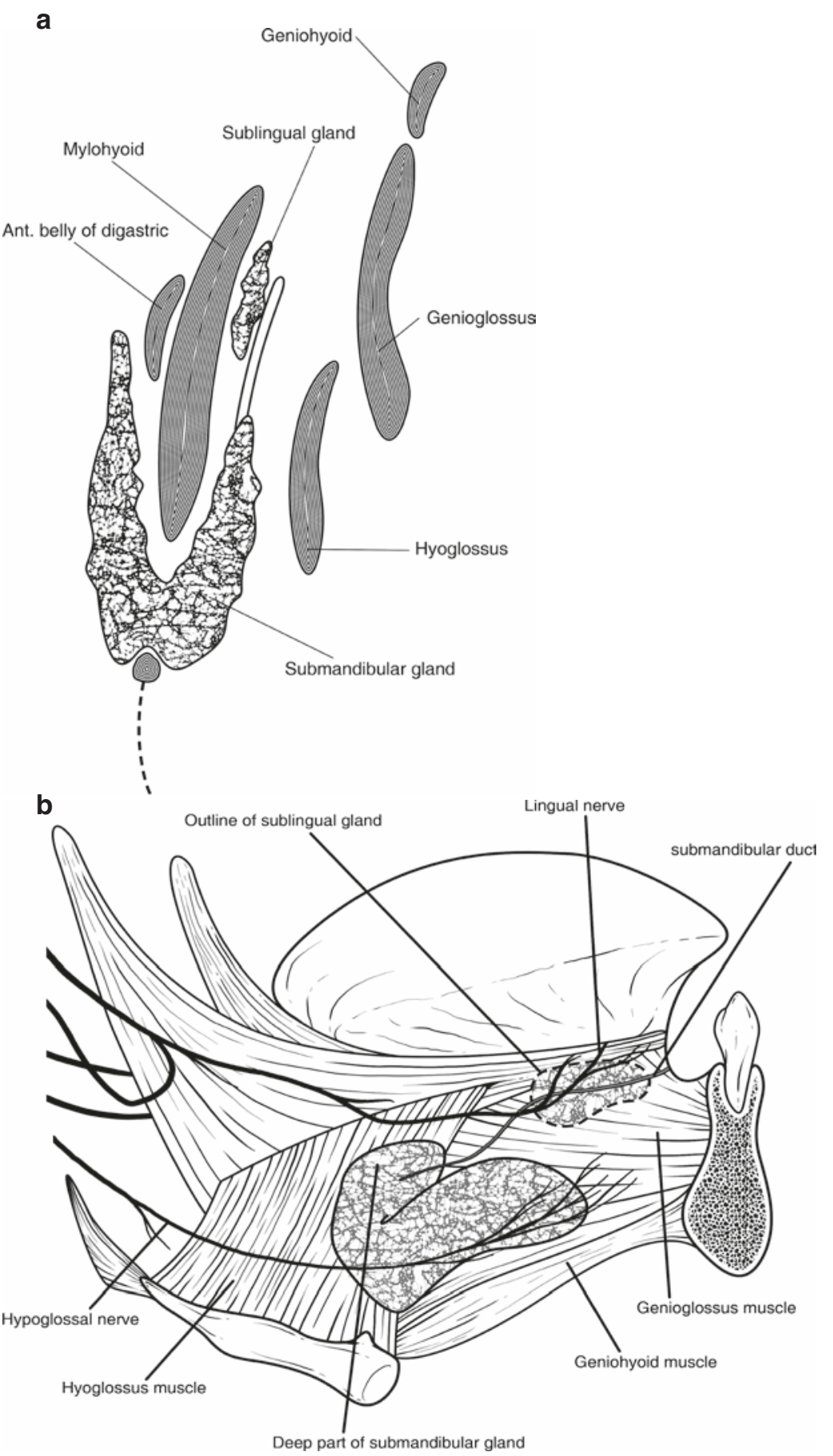

CAssociation of Oral and Maxillofacial Surgeons of India

\subsubsection{Sublingual Glands}

They are located beneath the mucosa of the floor of the mouth and appear as an elevation in the floor of the mouth. The excretory ducts of the sublingual glands are very superficially located and open in the floor of mouth at a superior level than the gland. Hence, they easily get damaged, and any trauma or infection of the ducts leads to salivary retention and formation of a mucous retention cyst which is called "ranula" due to its bluish color resembling the belly of a frog. The international statistical classification of diseases and related health problems shown in Table 46.4 . 
Table 46.4 International statistical classification of diseases and related health problems

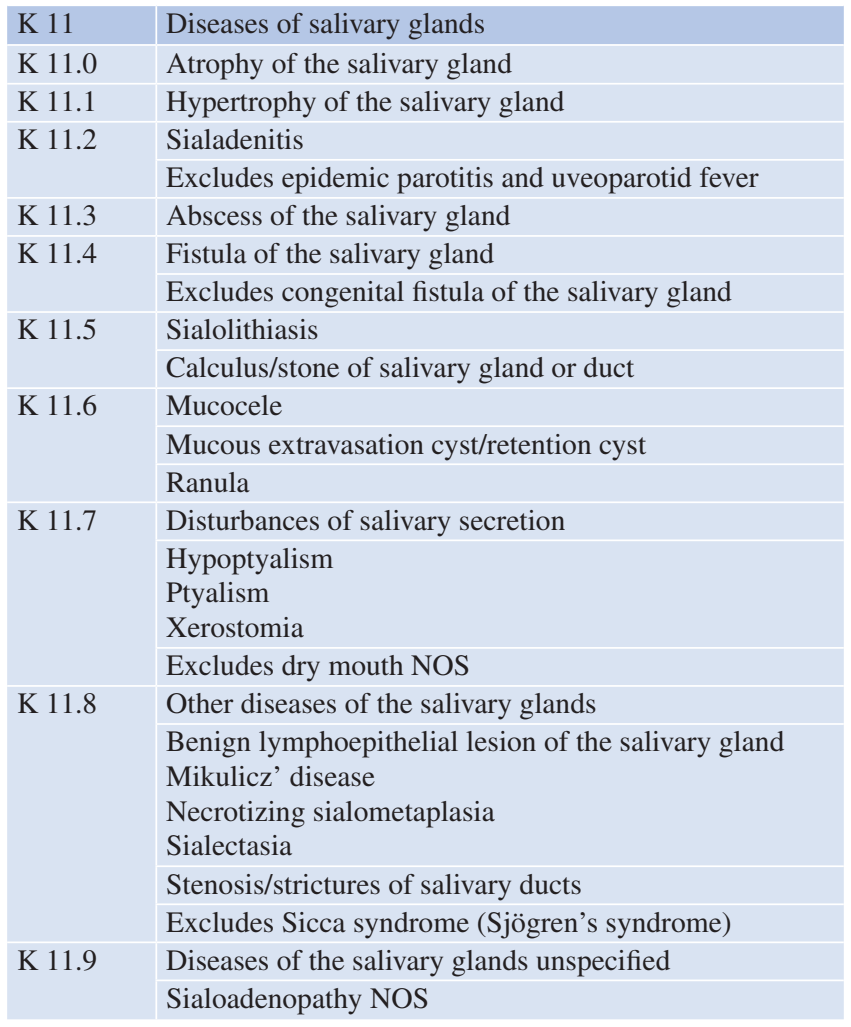

10th Revision (Version for 2003) [11]

\subsection{Diagnosis and Diagnostic Aids}

A thorough history followed by meticulous examination holds the key to proper diagnosis of salivary gland pathologies. Salivary gland neoplasms are usually slow growing and non-tender. A slow-growing swelling of the salivary gland is suggestive of a neoplasm, whereas a sudden, painful swelling is suggestive of an infective pathology although it can sometimes indicate a malignant tumor with secondary infection. Nerve weakness and skin infiltration are always associated with malignant tumors which have already infiltrated the nerve or skin although the vice versa is not always true.

Major salivary glands are palpated, and secretions milked out to check flow, quantity, and quality of secretion. A turbid salivary discharge may indicate an infection, whereas reduced salivary flow could indicate either less secretion or obstruction to flow. Function of facial nerve should be checked and documented during parotid examination. On inspection submandibular gland swelling can be easily identified and compared with the contralateral side; however the submandibular glands are bimanually palpated (Figs. 46.8 and 46.9).

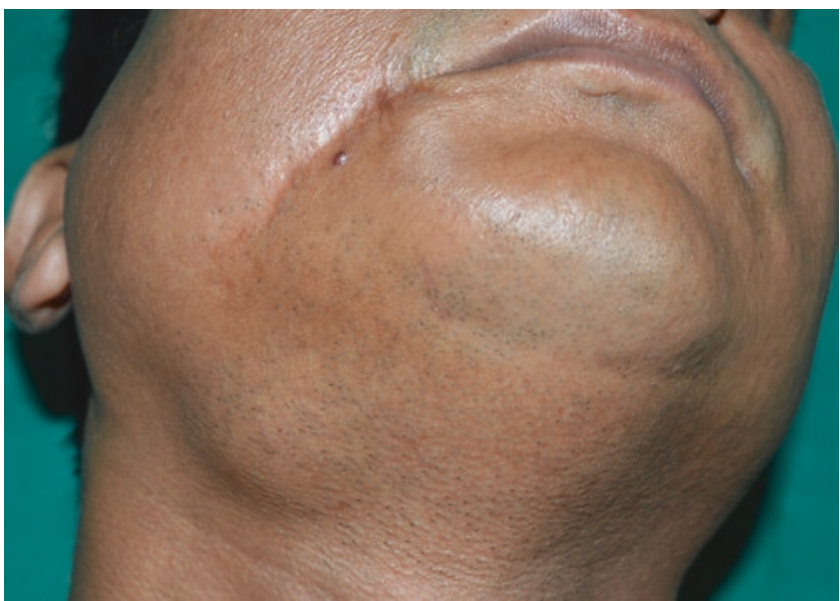

CAssociation of Oral and Maxillofacial Surgeons of India

Fig. 46.8 Clinical photo showing submandibular gland enlargement, right side

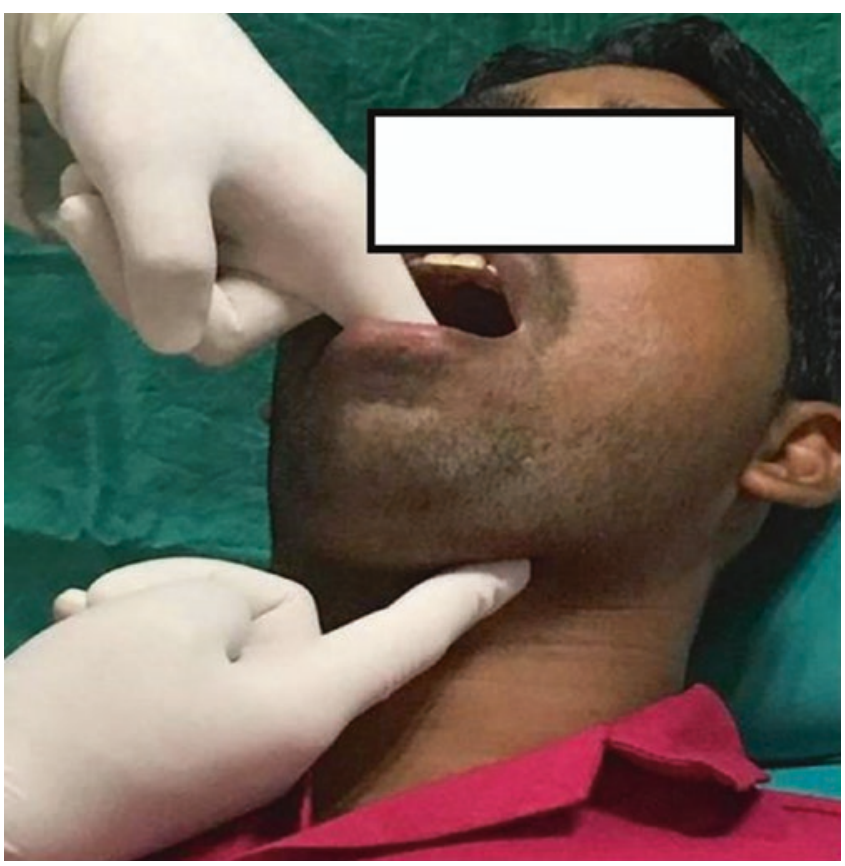

CAssociation of Oral and Maxillofacial Surgeons of India

Fig. 46.9 Bimanual palpation

Various diagnostic aids for investigating salivary gland diseases are as follows:

1. Diagnostic imaging

(a) Routine radiographs: It is useful only for diagnosing sialoliths and parenchymal calcifications. Radiopaque salivary calculi in the gland or duct can be picked up on plain films such as occlusal X-ray for submandibular gland and duct and a posteroanterior (PA) skull with blown-out cheeks for parotid calculi. 
(b) Ultrasonography: Ultrasonography (USG) is a noninvasive modality that utilizes non-ionizing radiation, gives good soft tissue discrimination, has excellent sensitivity for mass lesions, and can be repeated as frequently as required. Normal gland is relatively homogenously hyperechoic than adjacent muscle, and so is cyst and tumor from parenchyma $[12,13]$. It helps to distinguish a cystic lesion from a solid mass in space-occupying lesion (Fig. 46.10). USG with color Doppler is useful to rule out vascular lesions and also aids in assessing vascularity of lesions.

(c) Sialography: It assesses obstructive pathology by instillation of radiopaque contrast medium to locate obstruction in the ductal system. The technique is more or less obsolete now with the advent of MRI imaging. It is a technique which involves injection of a radiopaque dye into the ductal system of the major salivary glands and taking plain X-rays to see the pattern of the dye into the ductal systems. Most commonly the contrast dyes used are iodine based. They can either be lyophilic (oil based) or aqueous (water based or water soluble). Lyophilic (oil-based) contrast dyes include Lipiodol (iodized poppy seed oil) and Pantopaque (organic iodine compound). Aqueous contrast dyes include iothalamate (Conray) and metrizoate (Triosil). Aqueous-based dyes are most commonly preferred. Sialography is indicated to diagnose obstructive pathologies and duct anomalies, degenerative changes in the gland, chronic inflammatory conditions, and intra- and extraglandular tumors. It is contraindicated in acute infections of the gland and in case of allergies to the dye.

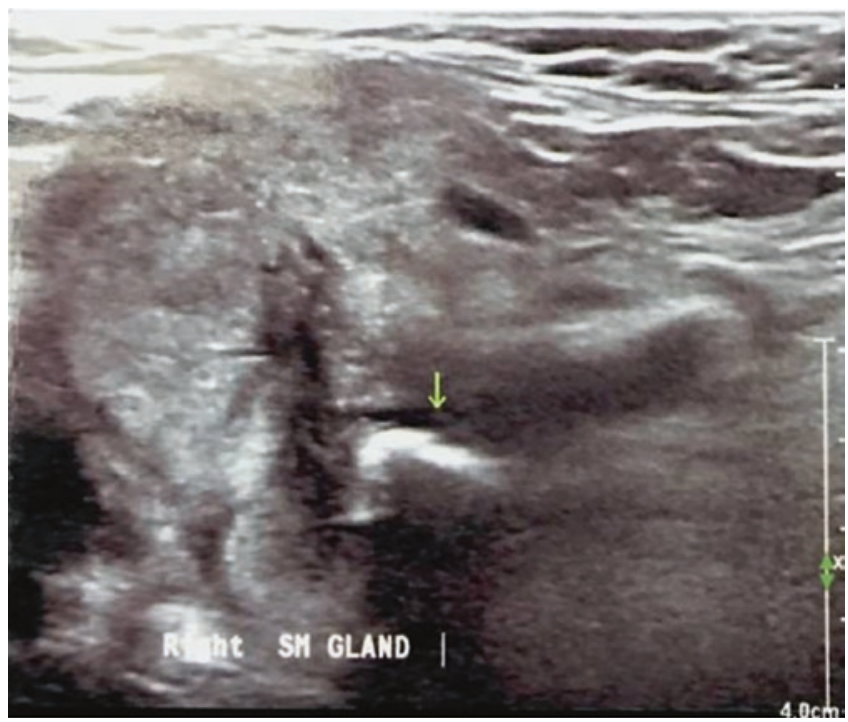

(CAssociation of Oral and Maxillofacial Surgeons of India

Fig. 46.10 USG of submandibular gland
Procedure: The duct orifice is enlarged using a lacrimal probe and cannulated with a 22 gauge cannula after infiltrating local anesthetic (Fig. 46.11a, b). The selected dye is injected into the ductal system using a Luer lock syringe with gentle continuous pressure with simultaneous massage of the gland. Once the patient feels some discomfort, dye injection is stopped. X-rays are taken during the filling phase and emptying phase as well.

The X-rays show different patterns:

(i) The normal parotid gland shows "tree in winter" or "leafless tree" pattern, and submandibular gland shows "bush in winter" appearance. This is because the normal acini do not allow dye to enter and it is seen only in the ducts and ductules (Fig. 46.12—normal sialography: leafless tree).

(ii) In chronic inflammation the dye enters the ductules, and the empty acini give a "blossom tree" or "leafy tree" appearance.

(iii) Sjögren's syndrome and Mikulicz' disease show a "snow storm" or "branchless fruit-laden" appearance.

(iv) Stricture in a duct is seen as a filling defect, whereas multiple strictures show a sausage string appearance.

(v) "Cannon ball" appearance is seen in intraglandular tumors, whereas extraglandular tumors show a "ball in hand" appearance.

(vi) Duct perforation and sialocele show dye spillage in the soft tissues.

(d) Radionucleotide scanning: It is used to distinguish between obstructive and nonobstructive sialadenitis. It involves both dynamic and static scanning. Radionuclide scanning is useful when a sialogram is contraindicated to distinguish between acute obstructive and nonobstructive sialadenitis [14].

(e) CT scan: It is used to evaluate masses in parotid glands and surrounding structures as it gives excellent soft tissue details (Fig. 46.13) especially when used with a contrast dye. Bony changes in the course of facial nerve like erosions, sclerotic margins, and widening of stylomastoid foramen or fallopian canal suggest involvement of nerve. Plain computed tomography (CT) scans have a major role to play for diagnosis of obstructive pathologies like a calculus.

(f) MRI scan: It allows assessment of salivary masses and early diagnosis of perineural spread due to excellent soft tissue contrast. In the case of neoplasms, it helps in demonstrating involvement of the facial nerve (Fig. 46.14).

(g) Arteriography: It assesses the vascularity and source of vascular supply of the tumors. 

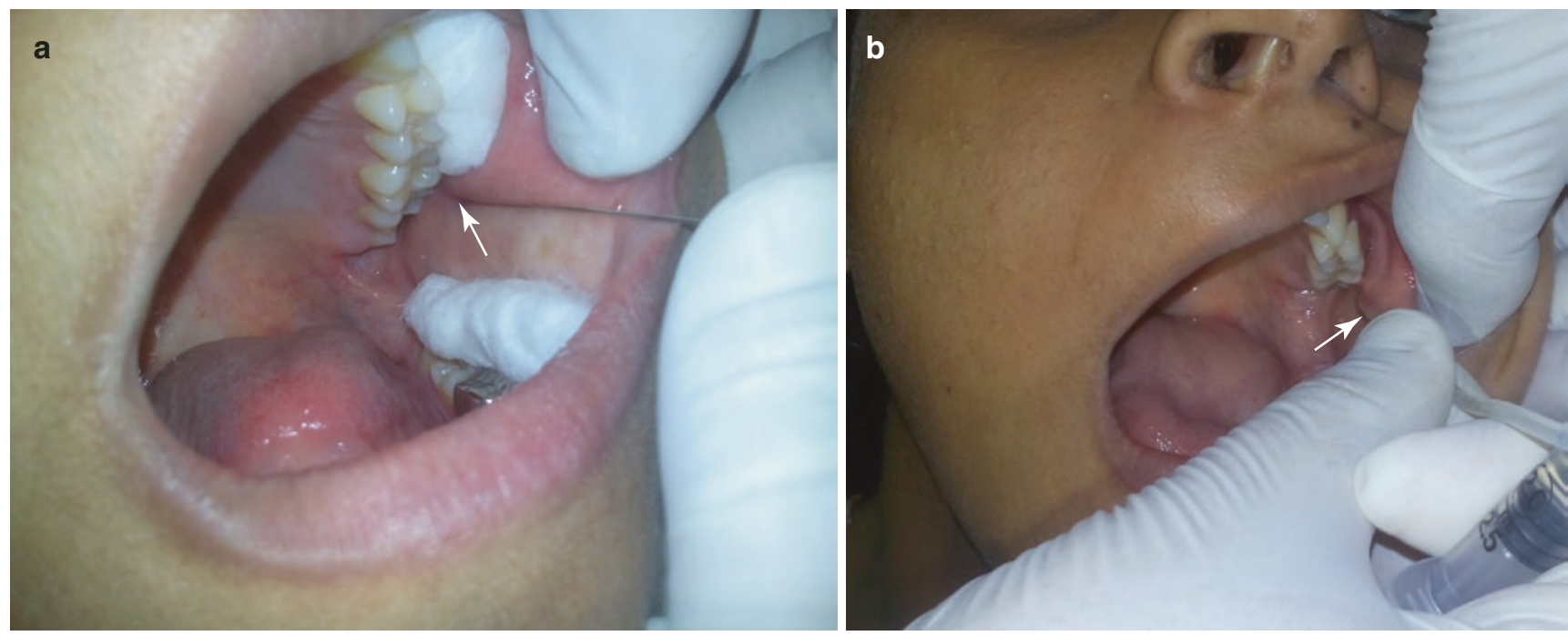

CAssociation of Oral and Maxillofacial Surgeons of India

Fig. 46.11 (a, b) Sialography technique

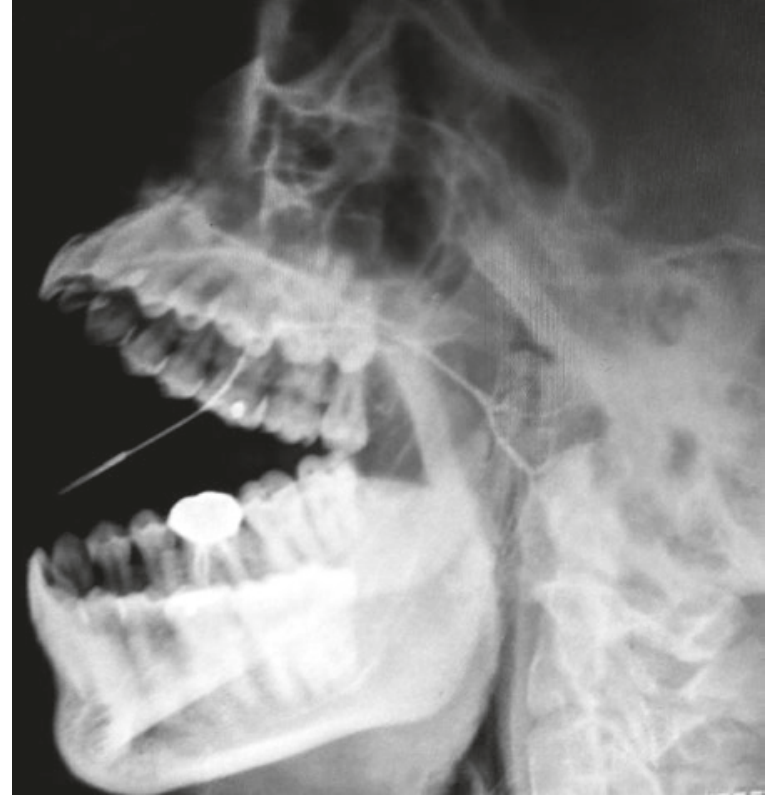

CAssociation of Oral and Maxillofacial Surgeons of India

Fig. 46.12 Normal parotid gland in sialography

(h) Positron emission tomography (PET): Uptake of radiotracer fluorodeoxyglucose used with PET scans by salivary glands makes this diagnostic technique useful for salivary gland tumors. Although this is an expensive technique, measurement of metabolic activity makes it more reliable than CT and MRI scans. It can be used to diagnose recurrences, tumor hypoxia, and proliferation rates [15].

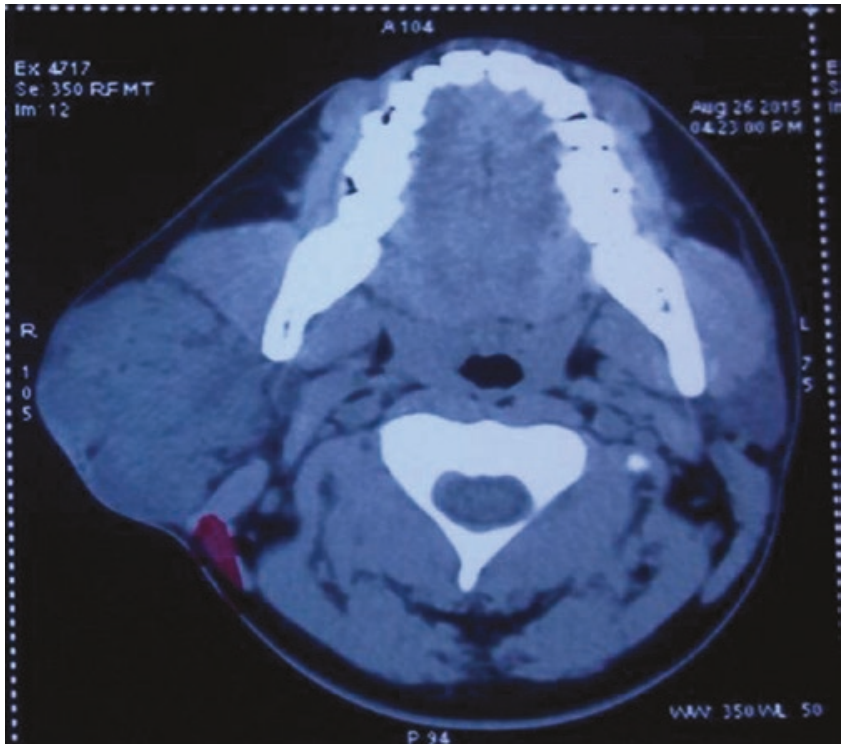

CAssociation of Oral and Maxillofacial Surgeons of India

Fig.46.13 CT scan showing parotid tumor

2. Histopathology: The gold standard of diagnosis for neoplasms will always be histopathology (HPE). However, as the major salivary glands are deeper structures, an FNAC (fine-needle aspiration cytology) is considered as a standard of care for diagnosis to avoid tumor seeding, which might follow an open biopsy. An open biopsy can be considered for minor salivary gland tumors or malignant tumors affecting major salivary glands with skin infiltration, needing skin excision to achieve surgical clearance. HPE for salivary gland 


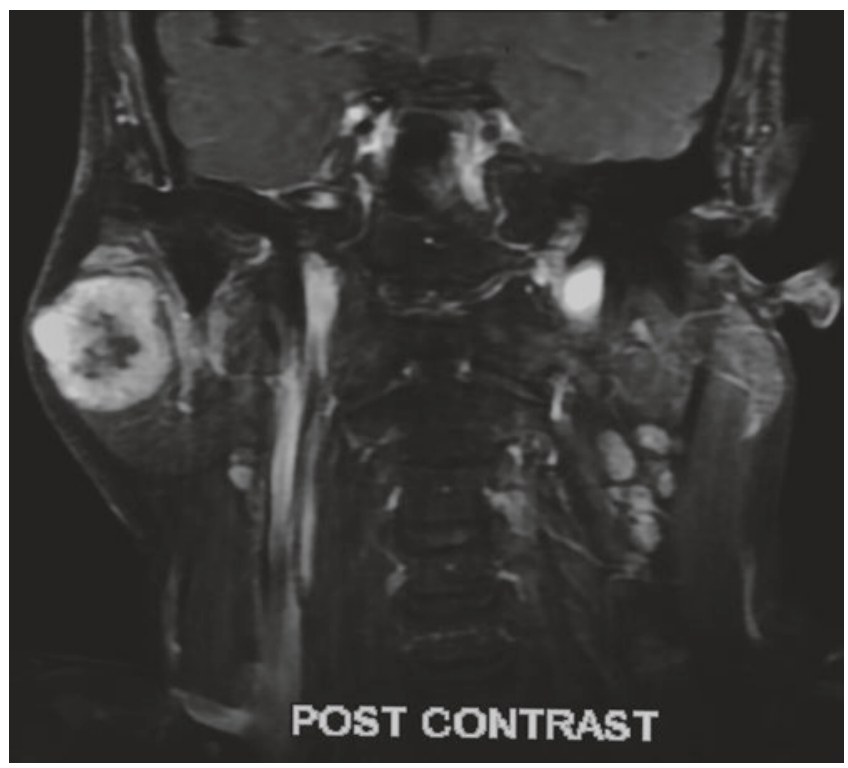

CAssociation of Oral and Maxillofacial Surgeons of India

Fig. 46.14 MRI showing parotid tumor, right side

pathologies is very challenging, and hence diagnosing lesions on FNAC is more difficult. It is important to distinguish benign and malignant pathologies on FNAC even if the exact malignant variant is missed, because except adenoid cystic carcinoma which has perineurial spread, the surgery doesn't change for any other malignant tumor variant.

(a) Fine-needle aspiration cytopathology (FNAC): It shows high diagnostic accuracy both for benign and malignant tumors. Complete histological features and status of invasion can't be revealed by this technique.

(b) Incisional biopsy: It is not a reliable technique as there is high possibility of seeding of tumor cells as well as fungation through skin.

3. Frozen sections: These help in diagnosing the nature of tumor, but accurate histopathologic features can't be diagnosed.

\subsection{Non-neoplastic Diseases (Table 46.5)}

\subsubsection{Acute Bacterial Sialadenitis}

Parotitis (Fig. 46.15) occurs secondary to decreased salivary secretions, and various reasons are attributed.
Table 46.5 Important terminologies in relation to salivary gland diseases

Sialadenitis: Sialadenitis is inflammation of the gland parenchyma. It could either be suppurative (with pus) or nonsuppurative (without pus). It can also be classified as acute, subacute, or chronic.

Sialodochitis: This refers to inflammation of the salivary gland duct. It may be associated with duct strictures and/or sialoliths.

Sialectasis: This refers to cystic dilatation of the ducts due to either a sialolith or ductal strictures. It is most commonly seen in parotid gland infections. It can occur due to any condition causing chronic inflammation of the gland.

Sialorrhea: This refers to excessive secretion of saliva or drooling of saliva. It is most commonly seen in patients with cerebral palsy and neuro-degenerative disorders.

Sialosis: It is defined as an asymptomatic, non-neoplastic, noninflammatory parenchymal salivary gland disease which manifests as persistent painless bilateral salivary gland swelling, most commonly involving the parotid gland [16].

Sialodochoplasty: It is repair of the salivary gland duct usually by translocating the ductal opening.

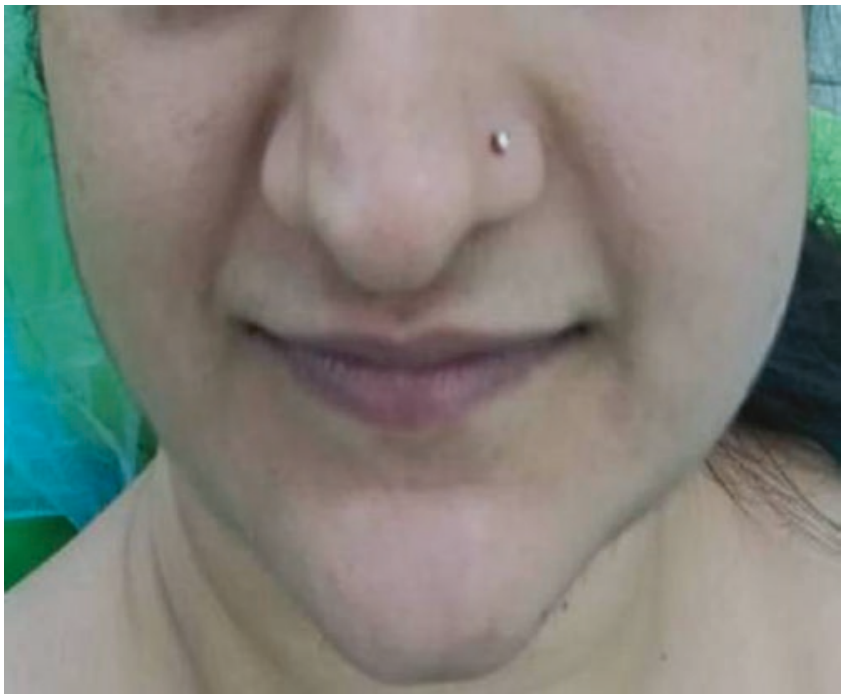

CAssociation of Oral and Maxillofacial Surgeons of India

Fig. 46.15 Parotitis left side

The common etiologic factors for parotitis are reduced salivary flow due to severe dehydration, in patients with debilitating diseases, old age, post-operative patients, post radiotherapy for head and neck cancers, poor oral hygiene leading to recurrent infection, mechanical obstruction to flow, compromised host resistance due to systemic illnesses like Diabetes Mellitus, renal failure, HIV, post transplant immunosuppresants. The drugs which induce systemic dehydration such as antihypertensives, diuretics, tricyclic antidepressants, phenothiazines, barbiturates, anticholinergics and betablockers also lead to reduced salivary flow rate [17]. 


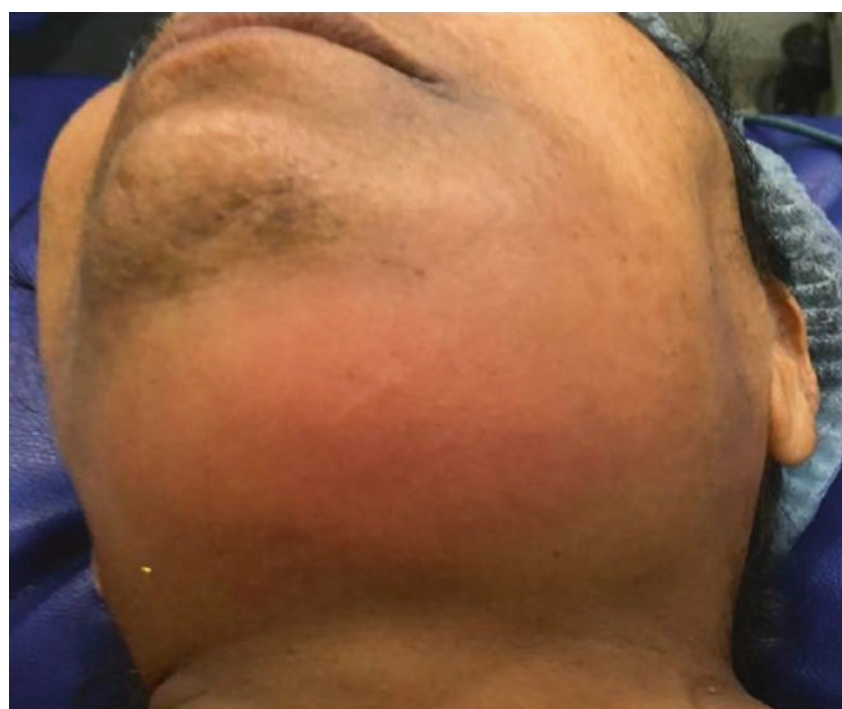

CAssociation of Oral and Maxillofacial Surgeons of India

Fig.46.16 Submandibular sialadenitis left side

It may be retrograde contamination of salivary ducts and parenchymal tissues by oral microflora providing a bacterial source of infection. Stasis of salivary flow through the ducts and parenchyma may also promote acute suppurative infection. There is a higher risk of sialolith in the submandibular duct causing secondary suppurative sialadenitis (Fig. 46.16 showing submandibular sialadenitis).

\subsubsection{Clinical Features}

- Sudden onset of pain and swelling, exacerbates with food sighting or smelling

- Generalized malaise, fever, body ache, and sometimes signs of dehydration.

- Diffuse inflammatory swelling, induration, erythema, edema, and extreme tenderness over the affected gland.

- Tense, glossy, and erythematous skin.

- Raised ear lobule is pathognomonic sign of parotid swelling.

- The duct orifices are inflamed, and milking of gland may exhibit lesser salivation or purulence.

- Systemic sepsis occurs more commonly in parotid sialadenitis as compared to submandibular sialadenitis.

- Parotid swellings are not fluctuant due to fixity of overlying investing parotideomasseteric fascia and are extremely painful due to the mounting pressure as the fascia is nonyielding. This mounting pressure leads to ischemic necrosis of the gland, and the abscess may spontaneously burst in the external auditory canal.
Routine blood count to rule out impending sepsis in addition to a plain radiograph or USG to rule out a sialolith in the duct is indicated. Sialography is contraindicated in cases of acute infections and also sialoliths. Aspiration might not yield frank pus.

\subsubsection{Management}

Treatment is managing underlying cause and adequate hydration and systemic antibiotics. If swelling doesn't subside with medical management in 2 days or shows an increasing trend, an incision and drainage is indicated. The cellulitic phase may not yield any frank pus, but toxic fluid is drained and it releases the pressure over the gland and prevents pressure necrosis of the gland parenchyma. Parotid space abscess has the tendency to spread into the pharyngeal spaces and cause respiratory distress and descending mediastinitis or burst into the auditory canal or TMJ and cause septic arthritis of the TMJ.

\subsubsection{Chronic Bacterial Sialadenitis [18]}

It is a recurrent sialadenitis with episodic relapsing swellings of the salivary glands, most commonly seen in the parotid gland. Salivary retention and stasis are the main predisposing factor. It might be preceded by an acute sialadenitis. Strictures may also form in the ducts leading to salivary stasis and eventually chronic sialadenitis. Generalized constitutional symptoms may be low grade, and salivary gland milking may yield scanty saliva. MRI is more specific than CT scan.

\subsubsection{Management}

Management consists of short-term corticosteroids to eliminate glandular inflammation followed by use of sialogogues to increase salivation and flush the debris. Sialoendoscopy can play a role in increasing the salivary flow.

The sialoendoscope is advanced slowly into the duct with continuous saline irrigation to help visualize the system and also dilating the strictures with help of the sialoballoon. This is followed up by placing a stent into the duct for 4 weeks.

Superficial parotidectomy with facial nerve preservation can also be considered in case of chronic pain, provided imaging studies determine the involvement of superficial lobe.

Chronic recurrent parotitis if left untreated may lead to benign lymphoepithelial lesion which can progress to lymphoproliferative disorders like non-Hodgkin's lymphoma, carcinoma, or pseudolymphoma. 


\subsubsection{Obstructive Disorders (Video 46.1)}

Sialolithiasis or salivary calculi are most commonly seen in the submandibular gland and duct (Fig. 46.17a, b). Symptomatic calculi are much lesser in occurrence. Only those cases with superadded infection and inflammation of the gland and duct result into pain.

\subsubsection{Etiology}

Salivary stasis is a major etiologic factor for formation of sialolith. The right-angle bend of the Stenson's duct where it pierces the buccinator and the $90^{\circ}$ bend of the Wharton's duct at the border of the mylohyoid is the common location for sialoliths. They can also result from chronic sialadenitis. Systemic abnormalities of calcium metabolism are not associated with any increased risk of salivary stone formations. Gout is the only systemic illness known to predispose to salivary stone formation [19].

Salivary stasis changes the mucoid element of saliva to a gel framework for deposition of salts and organic substances creating a stone. Unknown metabolic phenomenon increases salivary bicarbonate content altering the calcium phosphate solubility and leading to precipitation of calcium and phosphate ions [20]. Wharton's duct is longer than the Stenson's duct, and the submandibular gland is situated at a lower level than the opening of the duct. Hence the duct has to follow an uphill, tortuous course and drain against gravity. So stagnation of secretions is more common than parotid gland.

In the submandibular gland, the calculus results in sialadenitis, whereas in the parotid gland, sialadenitis causes calculus formation. In the parotid gland, stones are most commonly located at the hilum or parenchyma, whereas submandibular sialoliths develop in the duct [21]. Sometimes typically the sialolith is expelled out of the gland through the duct and is seen at the duct orifice.

\subsubsection{Diagnosis and Management}

Sialography can be used for diagnosis of sialoliths but is contraindicated if the calculus is already diagnosed on plain radiographs. Smaller stones can be expelled out through the

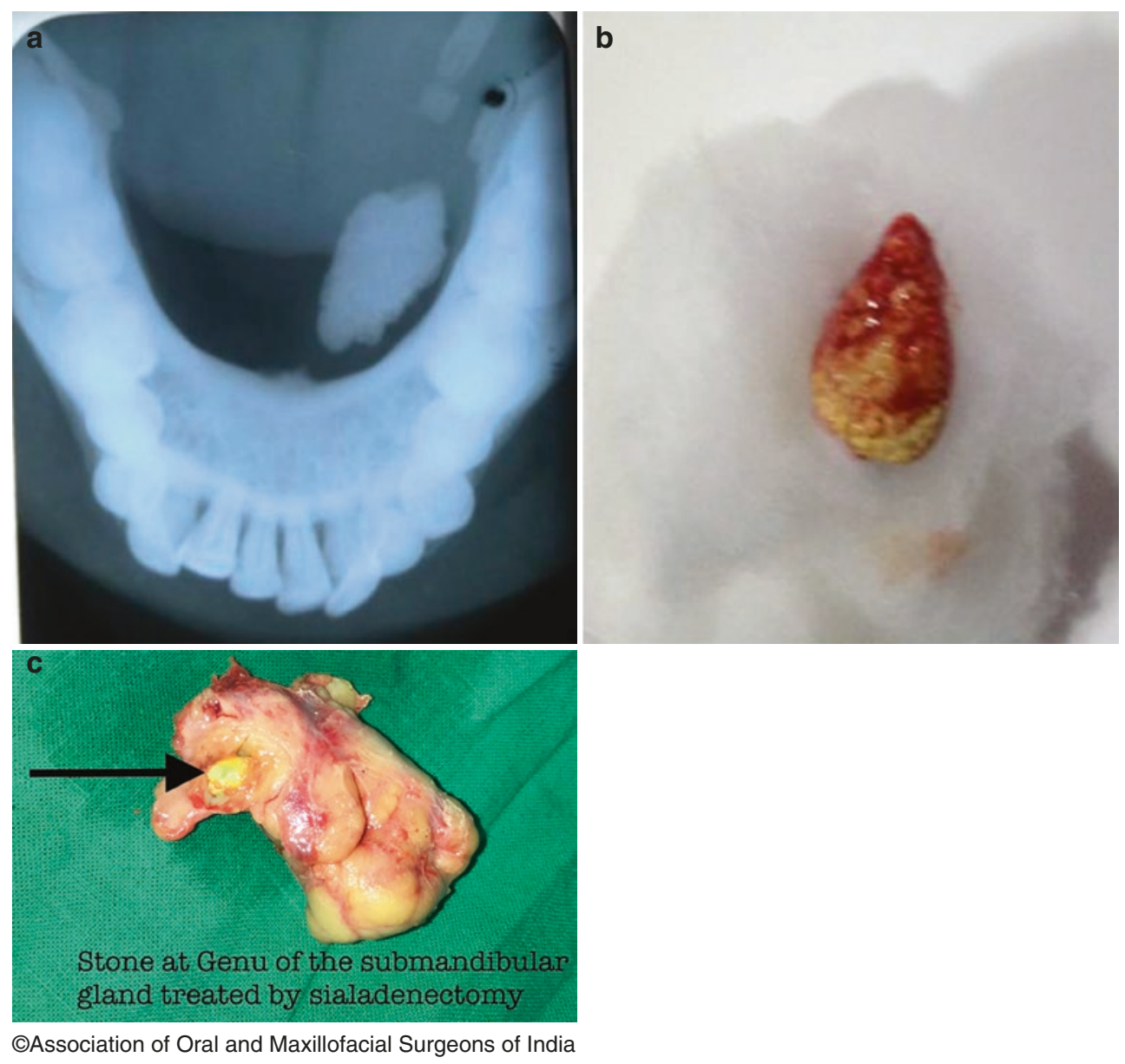

Fig. 46.17 (a, b) Left—Submandibular duct calculus (a). Right—Calculus after surgical removal (b). (c) Submandibular gland specimen showing calculus at the gene 
duct opening using local massage, sialogogues, and adequate hydration. Larger stones are managed surgically according to its location in the duct and gland.

If the stone is palpable in the oral course of the duct, the duct is dilated with a lacrimal probe and cut open to retrieve the stone. The duct margins are sutured to the adjacent mucosa to avoid stricture formation. A stay suture can be placed around the duct proximal to the stone to avoid accidental pushing of the stone into deeper inaccessible part of the duct. In submandibular stones which are at the genu of the duct or deeper into the gland, a sialadenectomy is needed (Fig. 46.17c).

If the sialolith is posterior in the duct, a suture is placed behind the stone to prevent slippage of stone into the duct. The incision is placed over the duct to extract the stone, and the duct is left without suturing (Fig. 46.18a, b).

Sialodochoplasty is a procedure wherein the incised duct margins are sutured with adjacent mucosa leading to a translocation of duct orifice [22, 23].

In the case of parotid sialoliths, only those in the duct distal to the masseter muscle can be accessed transorally and removed. All deeper stones warrant a parotidectomy.

Extracorporeal shock wave lithotripsy and use of sialoendoscopy are newer modalities to manage sialoliths. Lithotripsy reduces calculi to small fragments that are then flushed out of the duct with spontaneous salivation or use of sialogogue [24]. The primary requirement for salivary stone lithotripsy is a functional gland which produces saliva which will clear the fragmented stone. A "gum test" which involves chewing of a sour gum can be done to test the functionality of the salivary gland. If the salivary secretions are normal, a visible swelling in the region of the gland will be noticed. If the test is negative, the patient cannot be taken up for lithotripsy.

\subsection{Viral Infections of Salivary Glands}

\subsubsection{Mumps}

Mumps is an acute nonsuppurative viral parotitis caused by paramyxovirus also known as epidemic parotitis. The term "mumps" is derived from the Danish word "Mompen" which means mumbling (like an old man) and describes the difficulty with speech because of inflammation and trismus [17].

\subsubsection{Pathogenesis}

It is an endemic disease and spreads by airborne droplet dissemination. It has an incubation of 2-3 weeks followed by 3-5-day viremia. The virus localizes to the salivary glands, a

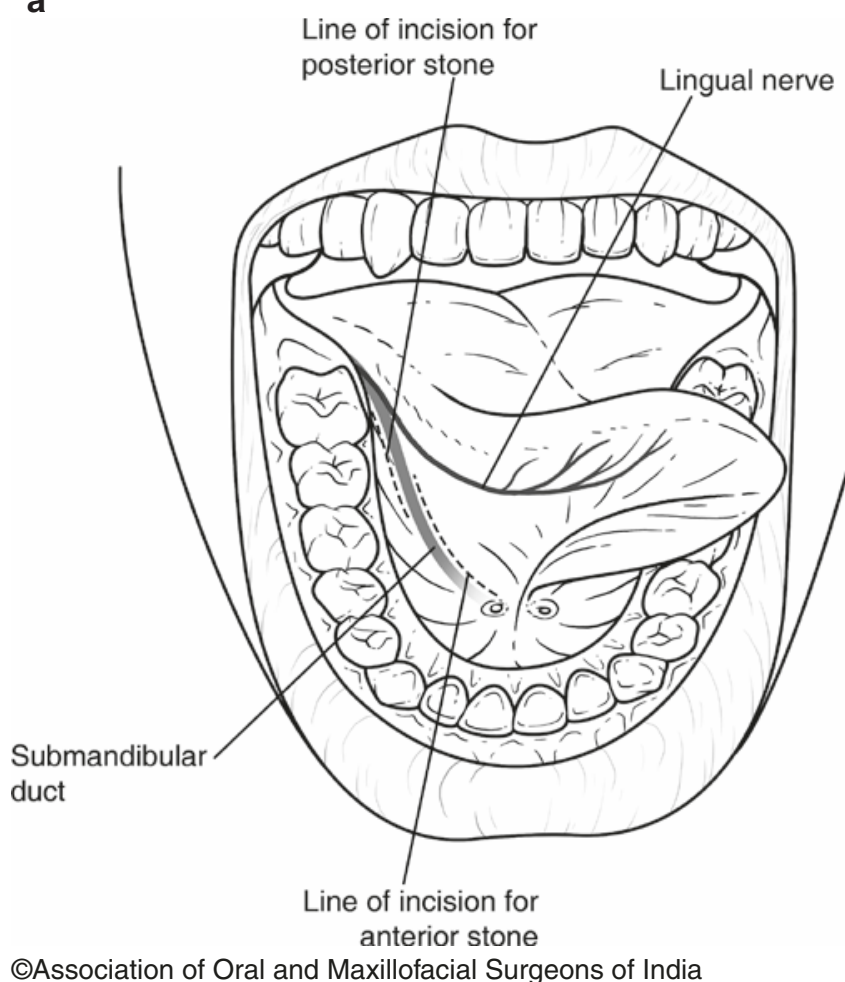

b

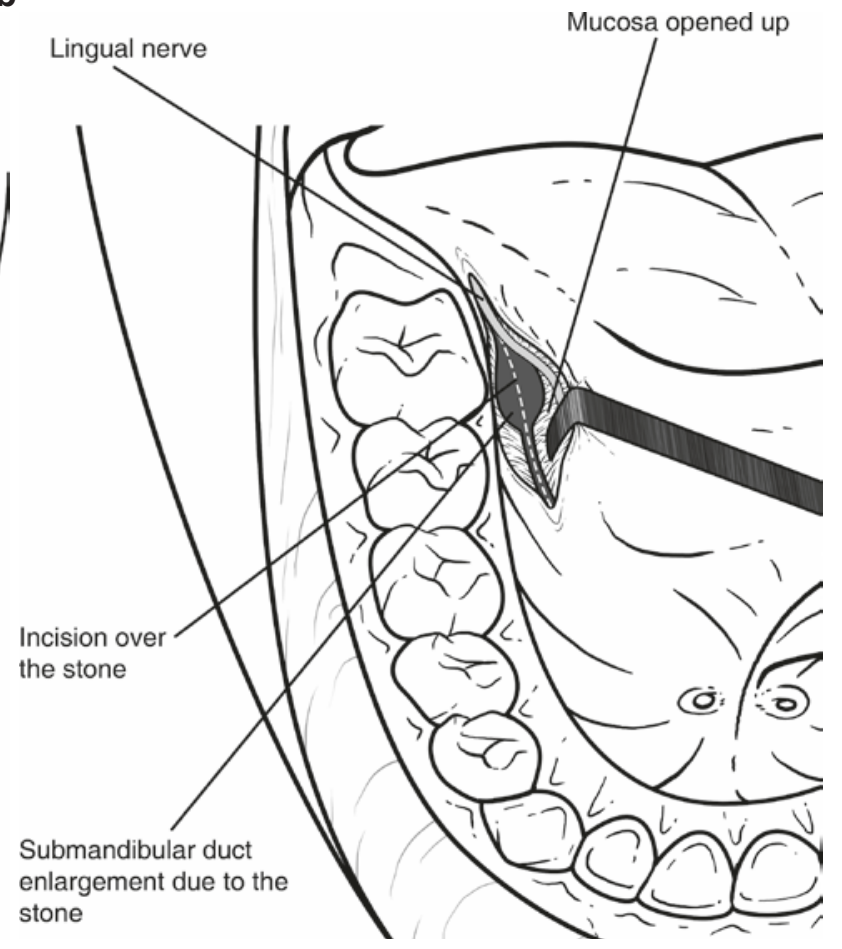

Fig.46.18 (a, b) Technique of sialolith removal from submandibular duct 
germinal tissues, and CNS [25]. The infection has a strong predilection for the parotid gland. It is highly contagious and occurs in children below 15 years of age with peak incidence being in the 4- to 6-year-old group of children [26]. Adults are rarely infected due to the immunity because of childhood exposure or due to the MMR vaccine [17].

\subsubsection{Clinical Features}

Prodromal symptoms include headache, myalgias, arthralgias, anorexia, and malaise prior to development of parotitis. It starts with an earache, pain around the gland, trismus, and dysphagia. Pain is exacerbated by salivary stimulation during meals. The parotid papilla may be inflamed and puffy. Palpation of the gland reveals a swelling of the gland which may be tense, rubbery, and firm with non-pitting-type edema. The overlying skin is tensed and shiny without erythema or increased local temperature. Swelling lasts for 1-5 days and can displace the pinna. Seventy-five percent cases result in bilateral involvement of parotid gland. However, it begins as a unilateral swelling and involves the contralateral gland after a period of 1-5 days [25].

Diagnosis is primarily clinical, but a blood count shows leukocytopenia with relative lymphocytosis. Serum amylase levels are also raised. It peaks during the first week and starts declining in the second or third week and comes back to normal later [25].

"S" or soluble antibodies directed against the nucleoprotein core of the virus appear within the first week of infection and peak within 2 weeks and disappear within 8-9 months. "V" or viral antibodies directed against the outer surface hemagglutinin appear several weeks after the "S" antibodies and persist at low levels for approximately 5 years following exposure. A fourfold rise in antibody titer is diagnostic of active infection. Mumps skin test is not useful in the diagnosis of acute infection because dermal hypersensitivity does not develop until 3 or 4 weeks following viral exposure.

\subsubsection{Treatment}

The disease is self-limiting, and treatment is primarily supportive such as rest, adequate hydration, antipyretics, and anti-inflammatory medicines.

Live attenuated Jerry Lynn vaccine is given combined with measles and rubella as MMR vaccine after 12 months of age. Immunized population is less likely to get the disease but may be infected with a nonparamyxovirus.

\subsubsection{Complications}

Orchitis and oophoritis can occur as systemic manifestations and rarely lead to complete sterility. Mastitis has been associated with decreased lactation. Aseptic meningitis occurs in
$10 \%$ of cases, and asymptomatic meningeal inflammation is more common. Five percent patients are affected by acute pancreatitis, wherein serum lipase levels are also increased. Sensorineural hearing loss complicates $0.05-4 \%$ of patients and may be permanent and profound [26]. Tinnitus, aural fullness, and vertigo are associated symptoms, but they resolve over a period of few weeks. Additional complications include myocarditis, polyarthritis, hemolytic anemia, plasmacytosis, lymphocytic leukemoid reactions, and thrombocytopenia [12]. These conditions are self-limiting or resolve with or without steroid therapy.

\subsubsection{HIV Parotitis}

HIV-associated salivary gland disease is the term used to describe the diffuse enlargement of the salivary glands that affects HIV patients throughout all stages of the disease. In fact, HIV-SGD may be the first presenting sign of HIV. Like most of the salivary diseases, the parotid gland is the most frequently affected. Clinically, HIV-infected individuals show reduced salivary flow rates. Parotid gland enlargement is reported to occur in $1-10 \%$ of the HIV-infected population. It is usually secondary to development of benign lymphoepithelial cysts within the parotid gland [25].

\subsubsection{Management}

Antiretroviral therapy with zidovudine, maintenance of oral hygiene, and use of sialogogues form the mainstay of management.

\subsection{Noninfectious Inflammatory Diseases}

Mikulicz' disease and Sjögren's syndrome are closely related to each other and are autoimmune in origin, wherein the salivary tissue itself becomes antigenic [27].

\subsubsection{Mikulicz' Disease}

\subsubsection{Clinical Features [28]}

Middle-aged females are affected commonly. It behaves like an inflammatory as well as a neoplastic disease. Presenting symptoms may be diffuse, poorly outlined, unilateral or bilateral enlargement of the parotid or submandibular glands with an occasional increase or decrease in size of the swelling. There is mild local discomfort, occasional pain, and xerostomia. Fever, upper respiratory tract infection, tooth extraction, or some other local inflamma- 
tory disorder may precede the disease. Sometimes the lacrimal glands may be enlarged. FNAC can help diagnose the condition.

\subsubsection{Management}

Mild cases once diagnosed do not warrant any treatment. In some cases, the swelling might regress spontaneously. Persistent cases can be managed by sialadenectomy [28].

\subsubsection{Sjögren's Syndrome}

Sjögren's syndrome or Sicca syndrome is a chronic autoimmune disorder of the exocrine glands involving multiple extraglandular sites and can even evolve into a lymphoid malignancy. Sjögren's syndrome shows a triad of symptoms-keratoconjunctivitis sicca, xerostomia, and a systemic disease, usually but not always rheumatoid arthritis. Primary Sjögren's syndrome also known as Sicca complex presents with only dry eyes and dry mouth. Secondary Sjögren's syndrome has in addition to the above features systemic manifestations such as systemic lupus erythematosus, polyarteritis nodosa, polymyositis or scleroderma, and rheumatoid arthritis [28].

Arthritis is the most frequent first complaint, followed by ocular complaints and then xerostomia which leads to difficulty in chewing and swallowing, sore mouth, recurrent dental caries, and fungal infections in the oral cavity. The tongue appears bald with loss of filiform papillae and fissuring of tongue. The saliva is usually cloudy due to pus and abnormally viscous due to gel-like consistency. Parotid gland enlargement is seen in 25-66\% cases of primary Sjögren's syndrome but is uncommon in secondary cases. Xeropthalmia leads to chronic irritation and destruction of the corneal and bulbar conjunctival epithelium, referred to as keratoconjunctivitis sicca. The patient complains of redness, itchiness, or burning sensation in the eye, rope-like secretions, dryness, and a foreign body sensation in the eye and may not be able to tolerate smoke, air draft, or light [27].

Schirmer's test is used to confirm lacrimal secretions. Patients complain of easy fatigue, general malaise, lowgrade fever, myalgias, and arthralgias. Respiratory tract symptoms range from dry cough due to xerotrachea to dyspnea due to interstitial disease or even airway obstruction. High-resolution CT scan shows bronchial and peribronchial thickening, whereas transbronchial biopsies show bronchiolar lymphoid infiltrates and follicular bronchiolitis [29]. Sensorineural hearing loss is associated with Sjögren's syndrome in 21-46\% of cases [30]. Dysphagia results from drying of the pharynx and esophagus. Other complications include renal disease, Raynaud's disease, inflammatory vascular disease, peripheral sensory or sensorimotor polyneuropathy or mononeuritis multiplex, skin dryness, vasculitis, and frequent allergic reactions. Labial salivary gland biopsy is used as a means of assessment of salivary pathology in Sjögren's syndrome.

\subsubsection{Management}

Xerostomia and keratoconjunctivitis sicca are managed by use of $0.5 \%$ methylcellulose artificial saliva and tears. Preventive dental care and fluoride application and maintenance of general hygiene are necessary. Eye patching and boric acid ointment can be used for corneal ulcers. Pilocarpine hydrochloride can be used as a secretagouge for management of xeropthalmia and xerostomia. Systemic corticosteroids can be used for systemic complications such as vasculitis, glomerulonephritis, and interstitial lung disease.

\subsubsection{Mucoceles (Video 46.2)}

Mucous retention cyst arises from ductal obstruction in a minor or accessory salivary gland due to traumatic severance of the duct due to biting of the lips, cheeks, and tongue or due to injury due to lip pinching during extraction. Majority of cases are an extravasation type of cysts which result from collection of salivary secretions in the soft tissues due to traumatic injury to the gland or duct. Lower lip was affected in $44-79 \%$ of cases. It occurs in any age with no gender predilection [31].

\subsubsection{Clinical Features}

Superficial lesions appear like a circumscribed, raised vesicle with a bluish translucent hue due to the thin overlying mucosa. However, deeper lesions being covered by normal mucosa have a normal color and texture. Mucoceles may get traumatized and rupture spontaneously and may recur later.

\subsubsection{Management}

Surgical excision of the mucocele along with a few normal minor salivary glands is the procedure of choice. Care should be taken to avoid creation of any other partially transected minor salivary glands which might give rise to the recurrent mucocele.

Mucocele can be excised by giving an elliptical incision around the lesion and closure (Fig. 46.19a-d), [32] or as the case requires, an incision may be given over the mucocele; lesion can be excised carefully without rupture and closure attained (Fig. 46.19e-h). 
Huang I et al. [33] recommended use of carbon dioxide laser vaporization to treat the lower lip mucocele with good results and less complications.

\subsubsection{Ranula}

Ranula is a mucocele arising from the sublingual salivary gland in the floor of the mouth (Fig. 46.20). It presents as a large blue, tense vesicle in the floor of the mouth. The appearance is of that of a frog's belly, hence the term ranula (frog belongs to genus Rana). It is firm on palpation. The cyst is usually present above the mylohyoid curtain, but when it presents in the upper part of the neck, it is called as a "plunging ranula." Plunging ranulas may grow to a sufficient size so as to compromise respiration and swallowing and may also extend into mediastinum [32].
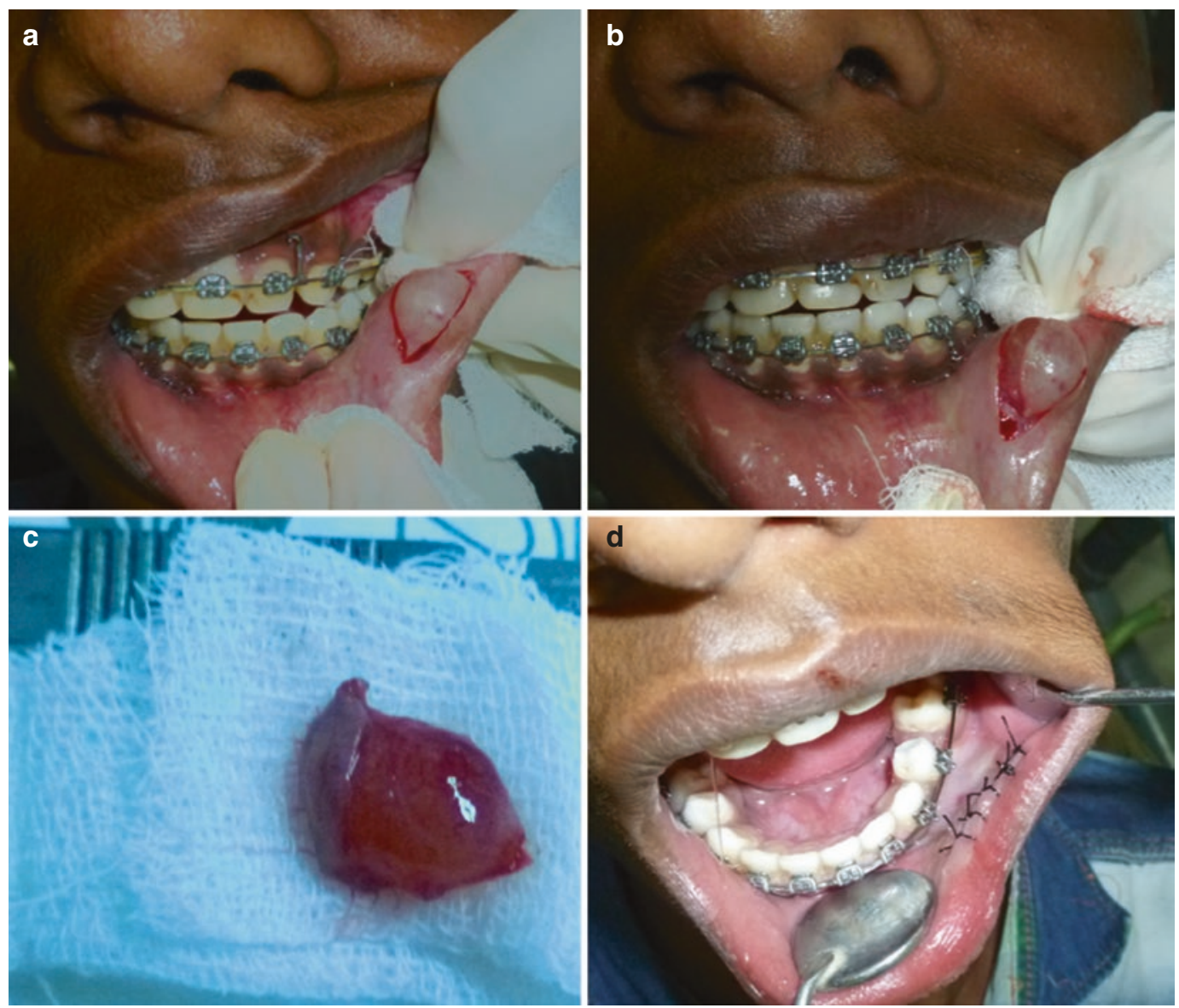

Fig. 46.19 (a)-(d) Figure showing surgical removal of mucocele by elliptical incision. (e)-(h) Figure showing excising mucocele by incision directly over the lesion

\subsubsection{Management}

Excision of the ranula and entire sublingual gland through a transoral approach is management of choice taking care to avoid damage to the lingual nerve. The incision is made through the mucosa in the lingual fold from the second molar to canine tooth. Blunt dissection is done up to the mylohyoid muscle. The gland is dissected free from the surrounding soft tissues and the Wharton's duct. The gland can be retracted using holding sutures, and blunt dissection is carried out till the lingual nerve is identified as it crosses the Wharton's duct. The gland is delivered once it is dissected free from the entire surrounding soft tissues taking care to prevent damaging the submandibular duct and lingual nerve [34].

Marsupialization can be used as an alternative modality wherein the ranula is deroofed and the mucosa sutured to the cystic lining followed by open packing of the cyst and sequentially reducing the size of the pack till it heals completely. 

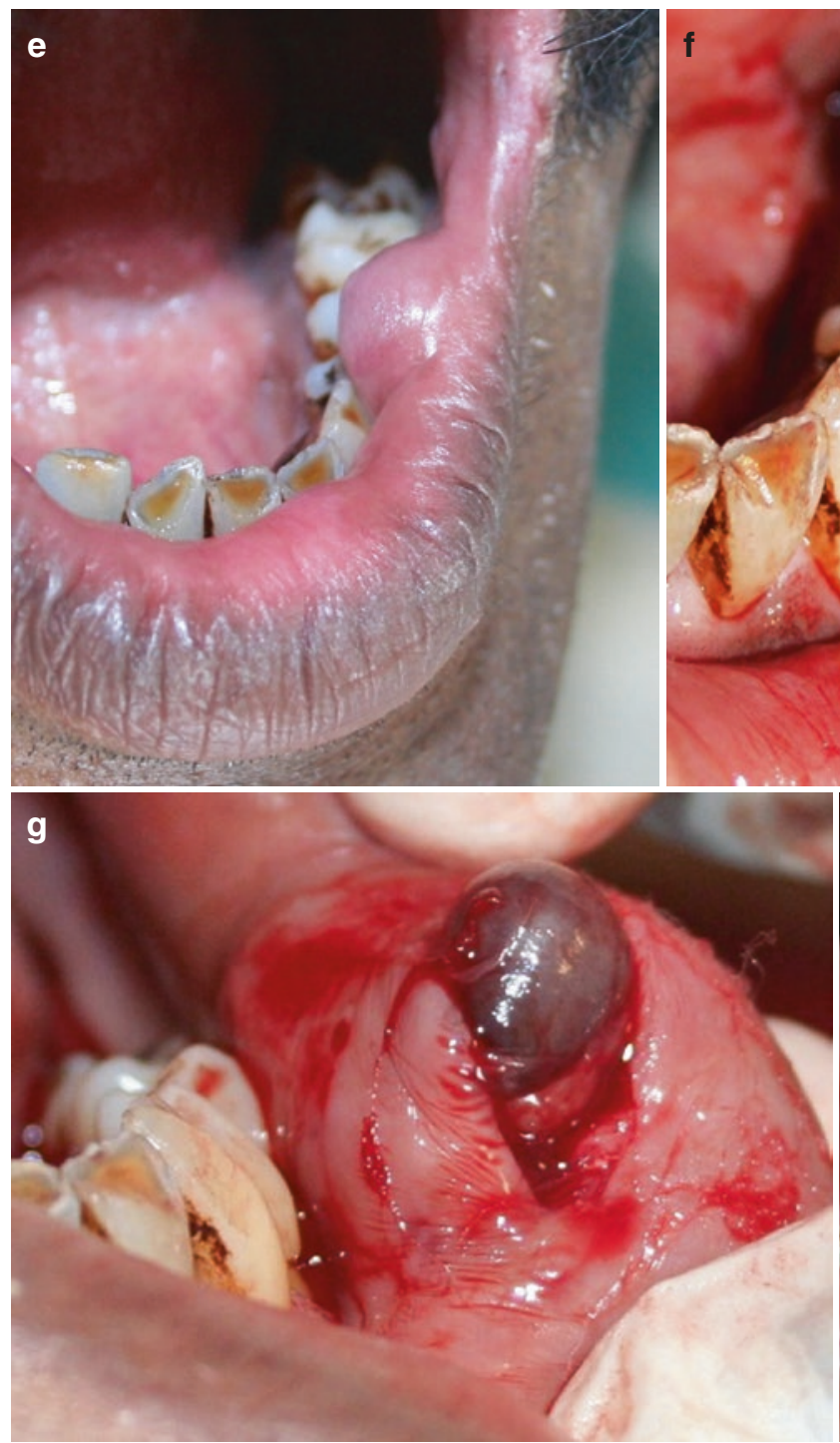

CAssociation of Oral and Maxillofacial Surgeons of India
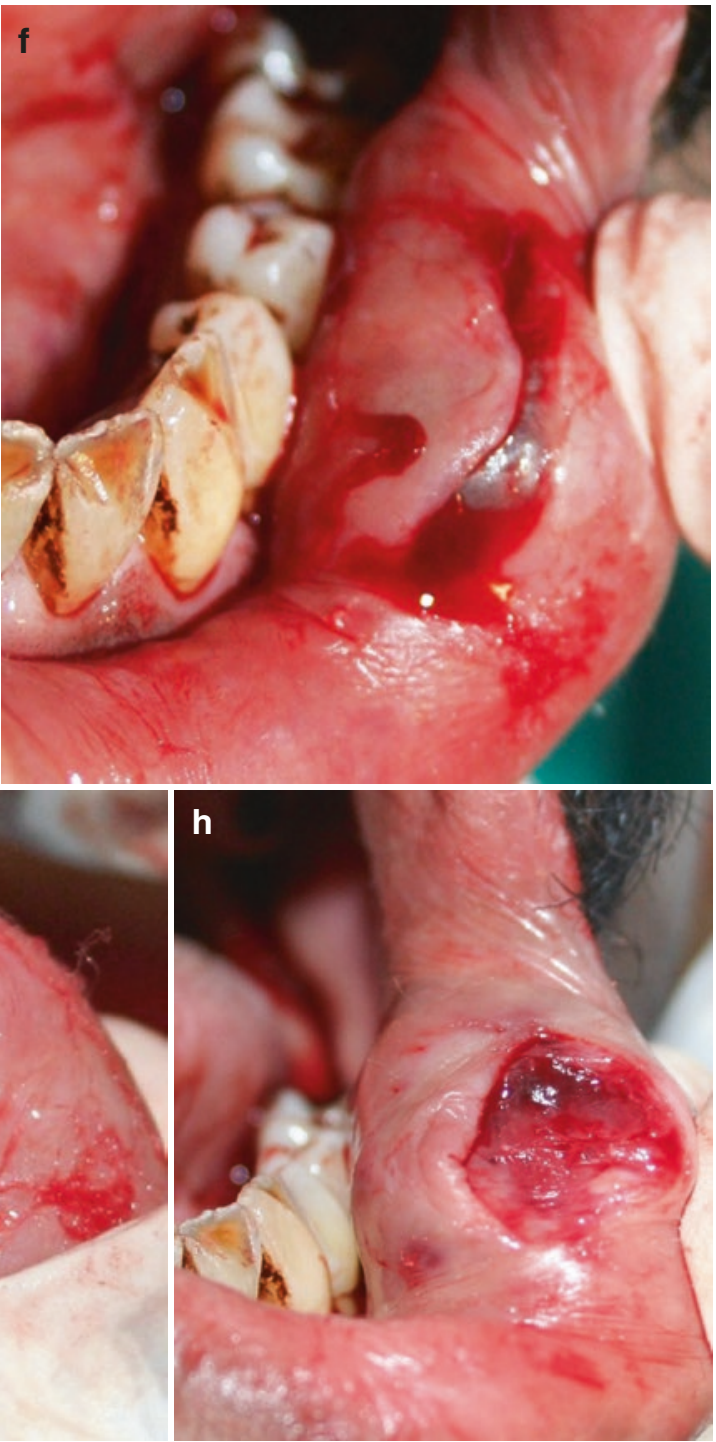

Fig. 46.19 (continued)

Higher recurrence rate (61-85\%) has been reported with simple marsupialization and ranula excision. To lower the rate of recurrence, total sublingual excision is the treatment of choice [35].

Kono et al. [36] recommended an injection of sclerosing agent, OK-432 (Picibanil), as a safe and effective method of treating intraoral ranulas. The number of injections used was 1-4 (mean 1.70) in their study.

\subsection{Salivary Gland Tumors}

\subsubsection{Etiology}

Although no specific etiology has been attributed to occurrence of salivary gland tumors, its association with radia- tions, viruses, hormones, lifestyle, or occupation and like factors can't be denied.

- Radiation: Evidence exists regarding susceptibility of lymphoid component rather than parenchymal component of gland to low radiation and UV ray damage (140 rad) [37-39].

- Viruses: It is believed that genetic component, environment, and immunity of host play a key role in malignant transformation of salivary gland tumors. Viruses like human papillomavirus, Epstein-Barr virus, cytomegalovirus, and polyomavirus have been speculated to be responsible for occurrence of salivary gland tumors.

- Hormones: Endogenous hormones play an important role in carcinogenesis of these tumors. Patients of breast cancer are more prone to salivary gland neoplasms. 


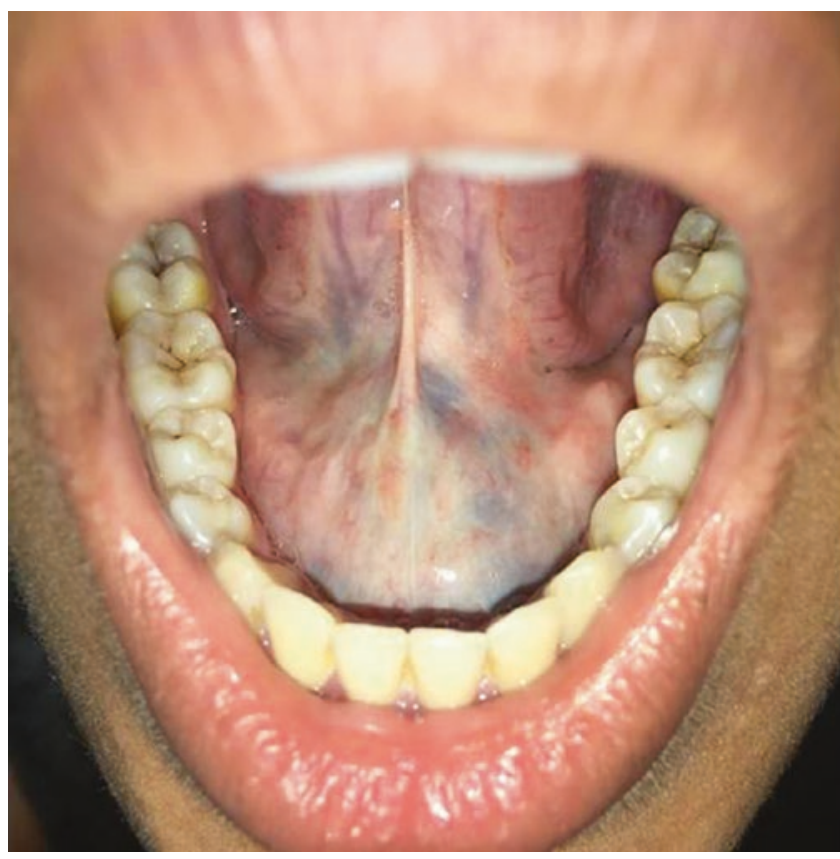

CAssociation of Oral and Maxillofacial Surgeons of India

Fig. 46.20 Ranula in the floor of the mouth

- Lifestyle: Tumors like Warthin's tumor or epidermoid carcinoma have been associated with cigarette smoking. Salivary gland enlargements are observed in nutritional deficiencies, but there are no reports of malignancies [40].

- Occupation: Those who engage in occupations which involve manufacturing and use of rubber products, asbestos mining, and plumbing are at increased risk of developing salivary gland tumors [37].

\subsubsection{Incidence}

Salivary gland tumors occur rarely both among Indian population and around the world. Incidence of benign and malignant salivary gland tumors in major portion of the world ranges from 1 to 2 cases per 100,000 people per year [41]. There is no specific predilection of occurrence of these tumors in any particular gender, although Warthin's tumor is more common in males and acinic cell tumor in females. Site wise incidence varies for both benign and malignant tumors. Seventy-five to eighty percent of benign tumors occur in the parotid glands, $5-10 \%$ in submandibular glands, and only $1-2 \%$ in sublingual glands. Malignant tumors are more common in sublingual glands $(80 \%)$ and least in parotid glands (17-20\%). Benign tumors affect a mean age group of 40 years, and malignant tumors affect an age group of 55 years. Both benign and malignant tumors by large resemble each other clinically. Hence, histopathologic examination is pivotal to establish a correct diagnosis.

\subsubsection{TNM Staging of Salivary Gland Tumors According to American Joint Commission on Cancer (AJCC) 2002 [42]}

Tumor $(T)$ : $\mathrm{T}$ with a letter/number describes the location or size of the tumor

$T X$ : Indicates the primary tumor cannot be evaluated.

$T 0$ (T plus zero): No evidence of a tumor was found.

T1: Describes a small, noninvasive (has not spread) tumor that is 2 centimeters $(\mathrm{cm})$ at its greatest dimension.

T2: Describes a larger, noninvasive tumor between $2 \mathrm{~cm}$ and $4 \mathrm{~cm}$.

T3: Describes a tumor that is larger than $4 \mathrm{~cm}$ but not larger than $6 \mathrm{~cm}$ and has spread beyond the salivary glands but does not affect the seventh nerve, the facial nerve that controls expression, such as smiles or frowns.

T4a: The tumor has invaded the skin, jawbone, ear canal, and/or facial nerve.

$T 4 b$ : The tumor has invaded the skull base and/or the nearby bones and/or encases the arteries.

Nodes $(N)$ : $\mathrm{N}$ is for lymph nodes. Lymph nodes of the head and neck region are regional lymph nodes, and those away from this region are distant nodes.

$N X$ : The regional lymph nodes cannot be evaluated.

NO: There is no evidence of cancer in the regional nodes.

N1: Cancer has spread to a single node on the same side as the primary tumor, and the cancer found in the node is $3 \mathrm{~cm}$ or smaller.

N2: Describes any of these conditions:

- N2a: The cancer has spread to a single lymph node on the same side as the primary tumor and is larger than $3 \mathrm{~cm}$ but smaller than $6 \mathrm{~cm}$.

- N2b: The cancer has spread to more than one lymph node on the same side as the primary tumor, and none measures larger than $6 \mathrm{~cm}$.

- N2c: The cancer has spread to more than one lymph node on either side of the body, and none measures larger than $6 \mathrm{~cm}$.

N3: The cancer found in the lymph nodes is larger than $6 \mathrm{~cm}$.

Metastasis $(M)$ : Describes the cancer that spreads to different body parts.

$M X$ : Indicates distant metastasis cannot be evaluated. 
MO: Indicates the cancer has not spread to other parts of the body.

M1: Describes cancer that has spread to other parts of the body.

\subsubsection{Classification of Salivary Gland Tumors}

Salivary gland tumors were first classified by WHO in 1972 . It was later modified in 1991 wherein the term "tumor" was replaced by "carcinoma" to denote acinic cell carcinoma and mucoepidermoid carcinoma [43]. It was further revised in 1997, and a greater number of entities of adenomas (myoepithelial adenoma, basal cell adenoma, canalicular adenoma) and carcinomas (acinic cell carcinoma, mucoepidermoid carcinoma, polymorphous low-grade adenocarcinoma, salivary duct carcinoma, myoepithelial carcinoma) were redefined with emphasis on the prognosis and therapy [44]. A revised classification was put forth by WHO in 2005 also. The latest classification of WHO which was given in 2017 consisted of the following changes:

- Secretory carcinoma, borderline tumor-sialoblastomaand sclerosing polycystic adenosis were added as new entities under malignant tumors.

- Simplification of terminologies of polymorphous adenocarcinoma, clear cell carcinoma, and intraductal carcinoma was done.

- Rare entities like adenocarcinoma, NOS, canalicular adenoma, and poorly differentiated carcinoma were regrouped (Table 46.6).

\subsubsection{Pleomorphic Adenoma}

"Pleomorphic adenoma" suggested by Willis closely resembles the unusual histologic pattern of the lesion [28]. The tumor derives its name from the Greek words Pleos = many and morphus $=$ form because of the heterogeneous nature of its histologic appearance [46].

\subsubsection{Clinical Features}

Most frequently found in the superficial lobe of the parotid gland, it presents as a firm, slow-growing asymptomatic mass which is smooth, rounded, lobular, and mobile with a rubbery consistency causing ear lobule to be raised (Fig. 46.21a). If the tumor involves both the superficial and deep lobes of parotid, it is classically referred to as dumbbell tumor. Incidence of the tumor except those found in the pharynx is more in females than males, and they are often seen in the fourth and fifth decade. A bilateral tumor occurrence rate is estimated at 1 in 40,000 [47].
Table 46.6 Revised classification of salivary gland tumors (2017) [45]

\begin{tabular}{|c|c|}
\hline Malignant Tumors & Benign Tumors \\
\hline Mucoepidermoid carcinoma & Pleomorphic adenoma \\
\hline Adenoid cystic carcinoma & Myoepithelioma \\
\hline Polymorphous adenocarcinoma & Basal Cell Adenoma \\
\hline $\begin{array}{l}\text { Epithelial-myoepithelial } \\
\text { carcinoma }\end{array}$ & Warthin's tumor \\
\hline Clear cell carcinoma & Oncocytoma \\
\hline Basal cell adenocarcinoma & Lymphadenoma \\
\hline Sebaceous adenocarcinoma & Cystadenoma \\
\hline Intraductal carcinoma & Sialadenoma papilliferum \\
\hline Cystadenocarcinoma & Ductal papillomas \\
\hline Adenocarcinoma, NOS & Sebaceous adenoma \\
\hline Myoepithelial carcinoma & $\begin{array}{l}\text { Canalicular adenoma and other } \\
\text { ductal adenomas }\end{array}$ \\
\hline $\begin{array}{l}\text { Carcinoma ex pleomorphic } \\
\text { adenoma }\end{array}$ & Other Epithelial Lesions \\
\hline Carcinosarcoma & Sclerosing polycystic adenosis \\
\hline Poorly differentiated carcinoma & Nodular oncocytic hyperplasia \\
\hline 1) Neuroendocrine and & Lymphoepithelial lesions \\
\hline non-neuroendocrine & Intercalated duct hyperplasia \\
\hline 2) Undifferentiated carcinoma & Soft Tissue Lesions \\
\hline $\begin{array}{l}\text { 3) Large cell neuroendocrine } \\
\text { carcinoma } \\
\text { 4) Small cell neuroendocrine } \\
\text { carcinoma }\end{array}$ & Hemangioma \\
\hline Lymphoepithelial carcinoma & Lipoma/sialolipoma \\
\hline Squamous cell carcinoma & Nodular fasciitis \\
\hline Oncocytic carcinoma & Hematolymphoid Tumor \\
\hline Borderline Tumors & $\begin{array}{l}\text { Extranodal marginal zone } \\
\text { lymphoma of MALT }\end{array}$ \\
\hline
\end{tabular}

Sialoblastoma

They are encapsulated and do not show fixity to the deeper tissues or the overlying skin in major salivary gland tumors, which can be confirmed on an MRI (Fig. 46.21b), but in the case of the minor salivary glands of the palate, it may appear to be fixed to the underlying palatal bone but does not invade or erode the bone. Pain is uncommon but $50 \%$ patients experience a pressure sensation. Accumulation of mucus can occur so that elastic swellings or frankly fluctuant cysts may form in the tumors.

In the case of the submandibular gland, palpation of the mass both extraorally and bimanually helps in localizing it and differentiating it from a lymph node, but FNAC is always needed to differentiate it from sialadenitis.

\subsubsection{Histopathology [48]}

On light microscopy morphologically complex and diverse cellular elements are seen. Both epithelial and myoepithelial elements are present. Based on cellular types, Foote and Frazel [49] have classified pleomorphic adenomas as follows:

- Principally myxoid (36\%)

- Equally myxoid and cellular (30\%)

- Predominantly cellular (22\%)

- Extremely cellular (12\%) 

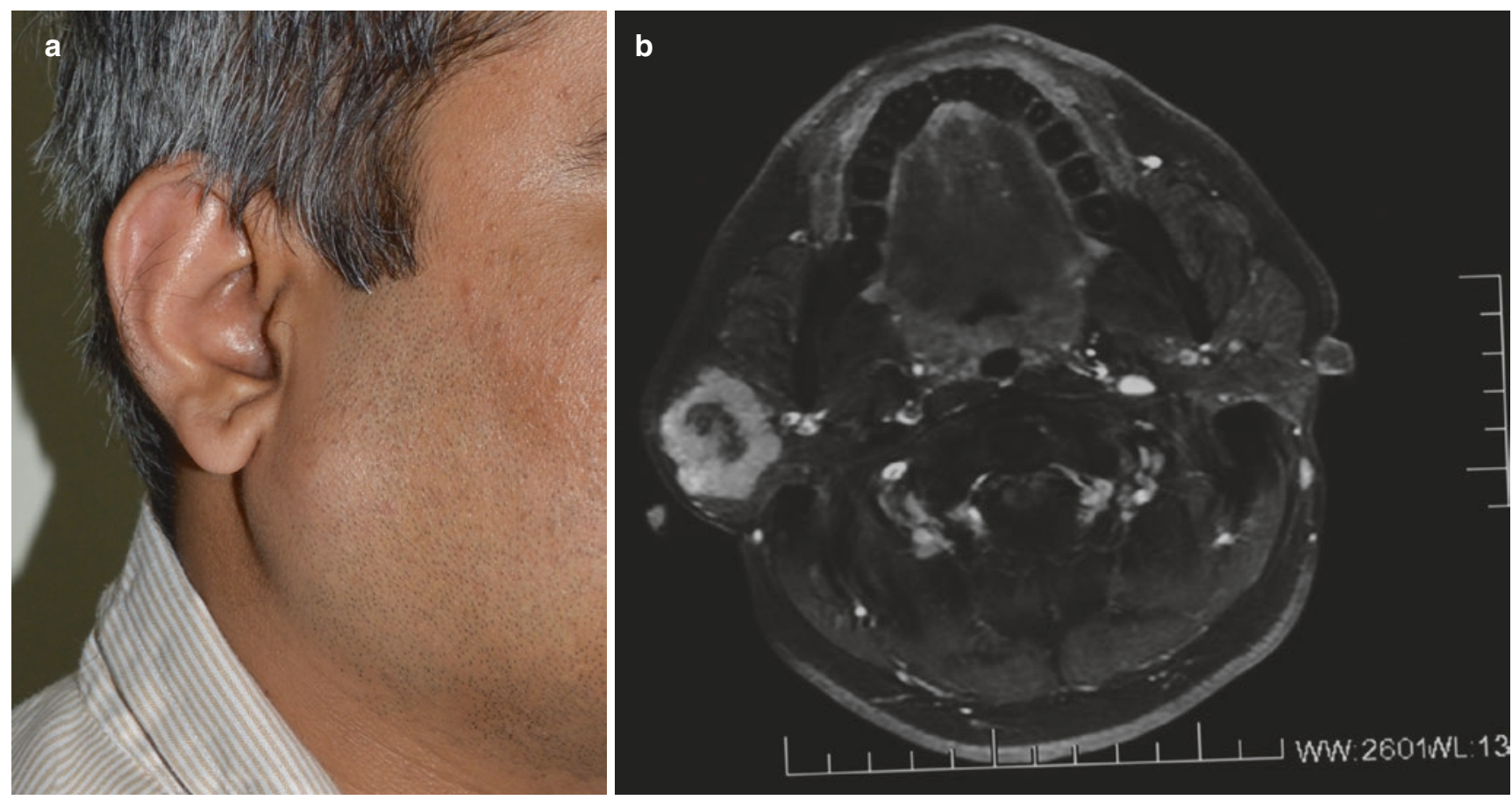

CAssociation of Oral and Maxillofacial Surgeons of India

Fig. 46.21 (a) Parotid tumor showing elevation of ear lobule (pathognomonic sign). (b) MRI axial view showing the tumor

\subsubsection{Management}

Surgical excision is the treatment of choice. Historically, enucleation was practiced which resulted in inadequate surgery and recurrences [50]. Superficial parotidectomy is the most widely accepted technique in the treatment of pleomorphic adenomas in the superficial lobe of the parotid gland, and total gland excision with facial nerve preservation is carried out. Tumors of the submandibular gland are usually contained within the gland, and their resection is usually confined to the gland and surrounding fat or lymph nodes until the neoplasm is a malignant and invasive tumor. As with the parotid gland, most neoplasms are asymptomatic. Small palatal pleomorphic adenomas usually cause pressure resorption of the palate but do not invade the bone. A disk of palatal mucosa is outlined well clear of the visible swelling because the tumor is flattened owing to the toughness of the palatal tissues. The tumor along with the periosteum of the palate is excised in continuity with each other. In case the pleomorphic adenoma invades the palate or proliferates into the floor of the maxillary sinus, a partial maxillectomy or total maxillectomy depending on the extension of the tumor has to be performed.

Although pleomorphic adenoma is a benign tumor, it may cause problems in clinical management due to its tendency to recur and risk of malignant transformation.

\subsubsection{Monomorphic Adenoma}

The WHO classification subdivides the monomorphic adenomas into three groups [45]:

- Adenolymphoma (Warthin's tumor)

- Oxyphilic adenoma (oncocytoma)

- Others

A number of other classifications of monomorphic adenomas have been put forth, but there is no unanimity. Two main histologic patterns have evolved:

- Basal cell adenoma

- Canalicular adenoma

\subsubsection{Warthin's Tumor}

Warthin's tumor, also known as papillary cystadenoma lymphomatosum and adenolymphoma, is the second most common benign tumor of the salivary glands, around $5 \%$ of neoplasms [51].

It was first described by Hildebrand in 1895 as a form of congenital cyst of the neck. It is known as Warthin's tumor in 
recognition of the pathologist who first described it in the USA in 1929. He described two cases and also coined the term papillary cystadenoma lymphomatosum [52].

\subsubsection{Clinical Features}

The majority of the tumors arise in the parotid gland, more often bilaterally, in the elderly and occurs in the fifth and sixth decades of life. A predilection for male sex is seen, more in Caucasians. Both tumors do not occur simultaneously but are metachronous in their manifestation. A concept of multicentric and multifocal disease has been put forth to explain this. It is a solitary, nodular, slowly enlarging swelling, most commonly located in the inferior pole of the parotid next to the angle of the mandible. It varies from moderately firm to fluctuant on palpation and is asymptomatic. It is not as discrete as the mixed tumor. Very few patients present with complain of pain, pressure, or rapid increase in the tumor size. Scintigraphy may be helpful due to its increased uptake of technetium$99 \mathrm{~m}$ pertechnetate. It appears as a smooth-margined, radiopositive "hot" nodule in contrast to the mixed tumors, nonfunctioning malignant tumors, and metastatic tumors which appear as a "cold" nodule in scintigraphy. Positive scintigraphy with ${ }^{123} \mathrm{I}$ is indicative of Warthin's tumor but may also signify presence of ectopic thyroid or metastatic thyroid tumor.

\subsubsection{Management}

Surgical removal is the established treatment for Warthin's tumor. As the tumor is superficial in the parotid gland, it is easily removed with minimal loss of glandular function and with preservation of the facial nerve.

Treatment philosophies given are:

- Tumor enucleation with resection of minimal amount of surrounding normal tissue

- Superficial parotidectomy, which is more aggressive than enucleation

- Local excision of parotid gland

Local excision of the tumor is preferred to enucleation of the tumor because lymph nodes at the posteroinferior part of the gland cannot be cleared by enucleation. Preoperative diagnosis of Warthin's tumor must be confirmed by coordinating the clinical findings with imaging and fine-needle aspiration biopsy reports before local excision is carried out. If there is associated chronic obstructive parotitis, superficial parotidectomy is essential. Similarly, if the tumor is located in front of the ear, a superficial parotidectomy is the treatment of choice.

\subsubsection{Oncocytoma}

An oncocytoma is a tumor characterized by large epithelial cells, i.e., oncocytes that contain a brightly eosinophilic, granular cytoplasm. The oncocyte is derived from the Greek word "onkousthai" meaning swollen or enlarged and was described in 1897 by Schaffer who observed this tumor in ductal and acinar elements of salivary glands in the tongue, pharynx, and esophagus. Jaffe was the first to introduce the term oncocytoma [53]. However, he had termed Warthin's tumor as oncocytoma. The other terminologies used to describe this tumor are oxyphilic adenoma and acidophilic adenoma.

\subsubsection{Clinical Features}

There is no race predilection for occurrence of this tumor. Oncocytoma is predominantly a tumor of the major salivary glands, parotid being the most common. Bilateral occurrence is also known. Among minor salivary glands, which are rarely affected, palatal mucosa followed by buccal mucosa and tongue is affected.

The oncocytoma is a small benign lesion which generally does not attain a great size. It most frequently presents as an indolent, single, often multi-lobulated, firm, solid, and mobile mass in the superficial lobe of the parotid gland. It can also be located in the deep lobe of the parotid gland and may be insinuated between the branches of the facial nerve. However, it does not cause any symptoms of pain or paresthesia unless the branches of the facial nerve are compromised. Tumor size varies with the duration of the lesion but generally does not increase beyond $4.0 \mathrm{~cm}$. Intraoral tumors do not exhibit any special characteristic diagnostic features. However, their overlying mucosa may become ulcerated due to trauma [53].

\subsubsection{Management}

Partial parotidectomy with facial nerve preservation whenever possible is the treatment of choice. It ensures complete removal of the tumor and reduces the rate of recurrence. Curettage or simple enucleation of the tumor is to be avoided to avoid recurrence. Complete sialadenectomy is the treatment of choice in cases of submandibular gland oncocytomas. In the case of minor gland tumors, local excision of the tumor with a margin of normal tumor-free tissue is carried out. Radiation therapy after surgery has been tried but it has shown to be ineffective.

\subsubsection{Basal Cell Adenoma}

It was first reported as a separate entity by Kleinsasser and Klein in 1967 [28]. 


\subsubsection{Clinical Features}

Basal cell adenomas occur between the third and ninth decade, but the peak incidence is in the sixth decade with a slight male predilection of 5:1 [28]. They are clinically indistinguishable from mixed tumors and occur in the superficial portion of the parotid gland. They are slow-growing, painless, round or ovoid, well-circumscribed, and freely mobile masses with a smooth-surfaced capsule and a soft to moderately firm consistency. They may be mistaken for a hyperplastic lymph node because of their encapsulation, size, and color.

Clinically basal cell carcinoma of skin, ameloblastoma, pleomorphic adenoma, and adenoid cystic carcinoma can be considered in the differential diagnosis.

On the basis of histopathologic appearance, they may be divided into four subtypes:

- Solid

- Trabecular

- Tubular

- Membranous

\subsubsection{Management}

Surgical excision with a sufficient clear margin of normal tissue is the treatment of choice.

\subsubsection{Canalicular Adenoma}

\subsubsection{Clinical Features}

It is seen between the fourth and ninth decade, highest incidence being in the seventh decade with a female/male ratio of 1.7 to 1.0 and a higher incidence in Caucasians. It is seen more commonly in the minor salivary glands of the lip and cheek and rarely affects the major salivary gland [54].

It presents as a non-ulcerated, painless, mobile nodule that exhibits slow growth unless it is traumatized, wherein there is presence of ulceration. Clinical appearance is similar to that of a mucocele [54]. The overlying mucosa may be normal colored or bluish.

In the case of upper lip lesion, a sialolith, mucocele, mucous retention cyst, and pleomorphic adenoma can be considered in the differential diagnosis.

\subsubsection{Management}

Surgical excision, enucleation, or limited extracapsular excisions have been used as treatment modalities in these tumors with success.

\subsubsection{Sialadenoma Papilleferum}

First described by Abrams and Finck in 1969, it was termed sialadenoma papilleferum because of its histologic similarity to syringocystadenoma papilleferum of skin adnexal origin [55].

\subsubsection{Clinical Features}

Sialadenoma papilleferum presents as a subcentimetric, asymptomatic, exophytic, papillary surface lesion which can be confused with squamous papilloma. The most common site of occurrence is the minor salivary glands at the junction of soft and hard palate with the tumor located on one side of the midline. This tumor occurs at an average age of 56 years, cases being reported from 2 years to 87 years. Male predilection is seen in the ratio of 1.5 to 1 . However, there is no racial predominance [55].

Clinically it resembles a squamous papilloma, and a differential diagnosis of verrucous carcinoma or a warty dyskeratoma needs to be considered.

\subsubsection{Management}

Being small, these tumors are easily excised usually with a clinical diagnosis of a squamous papilloma. However, recurrence is rare.

\subsubsection{Inverted Ductal Papilloma}

Inverted ductal papilloma is a rare tumor and was first described by White et al. in 1982 when they reported four cases [56].

\subsubsection{Clinical Features [56]}

It occurs as a firm, asymptomatic, discrete nodule of $1-1.5 \mathrm{~cm}$ beneath the normal mucosa which in some cases may be contiguous with a small surface pore. The mean age of occurrence is 50 years without any sex predilection. The sites usually involved are the lower lip and buccal vestibular mucosa in descending order with occasional cases reported in the upper lip, floor of mouth, and soft palate.

\subsubsection{Treatment and Prognosis}

It is treated by simple surgical excision as it is not known to recur.

\subsubsection{Intraductal Papilloma}

It is a rare tumor. These tumors present as asymptomatic, submucosal swellings that vary in size from less than 1 to $1.5 \mathrm{~cm}$ in the minor salivary glands. The ages of patients range from 29 to 77 years, with a mean age of 54 years. Men and women are equally affected.

\subsubsection{Treatment and Prognosis}

Excision is curative, and these tumors are not known to recur. In case the tumors are small, all types of papillomas of the 
minor salivary glands, including intraductal, inverted, and sialadenoma papilliferum, can be excised in the dental office or the clinic under local anesthesia [55].

\subsubsection{Mucoepidermoid Carcinoma}

Mucoepidermoid carcinoma is the most common malignant salivary gland neoplasm. They are classified as grade I (low grade) which are well differentiated, grade II (intermediate grade) which are moderately differentiated, and grade III (high grade) which are poorly differentiated tumors.

\subsubsection{Clinical Features}

Mucoepidermoid carcinomas occur more commonly in the minor salivary glands with a female predilection [57]. It occurs as a painless, circumscribed, mobile solitary enlargement of the body or tail of the parotid or the submandibular region with over a year duration generally. Pain, facial paralysis, and fixation to the overlying skin are usually suggestive of high-grade lesions [57]. Minor salivary gland lesions present as a bluish or red-purple, fluctuant, smooth-surfaced mass that is often clinically mistaken for a mucocele or hemangioma [57]. Large lesions at the base of the tongue or in the oropharynx may cause dysphagia. Aggressive tumors show ulceration. Numbness of the teeth may occur when the bone is involved. Histopathologically, mucoepidermoid carcinomas are graded as low-grade, intermediate-grade, and high-grade carcinomas. They are generally partially encapsulated and don't show adequate circumscription.

\subsubsection{Management}

Complete, adequate, and radical surgical excision is the treatment of choice for all grades of mucoepidermoid carcinomas [58]. In the case of stage I and stage II mucoepidermoid carcinomas of the parotid gland, conservative excision with preservation of the facial nerve, if possible, is recommended. The affected submandibular gland should be removed entirely. Radical neck dissection is performed in patients with clinical evidence of cervical node metastasis and is considered in any patient with a T3 lesion. In the case of facial nerve involvement, total parotidectomy with facial nerve sacrifice up to histologically tumor-negative nerve trunk is done. The 5-year disease-free rate in patients receiving this aggressive treatment was about $60 \%$ [58].

Treatment of minor salivary gland mucoepidermoid carcinomas entails a wide surgical excision with the bone if involved, to achieve a negative margin, and the wound is left to heal secondarily [59]. For small low-grade tumors in the absence of bone involvement, wide excision down to periosteum with 1 or $2 \mathrm{~cm}$ tumor-free lateral margins is adequate therapy [59]. High-grade and advanced stage tumors must be treated aggressively at any site. The overall recurrence rate of mucoepidermoid carcinomas is approximately $25 \%$. Better survival is seen among younger patients and among females. Tumors in the submandibular gland and in the base of the tongue generally have a poorer outlook than those at other major and minor salivary gland sites. Also invasion into bone signifies a poorer prognosis. Survival is closely related to the clinical stage and the histologic grade.

\subsubsection{Adenoid Cystic Carcinoma}

Adenoid cystic carcinoma (ACC) is a highly aggressive, destructive, and clinically unpredictable tumor of the head and neck region [60]. The other terms used for ACC used in the past are cylindroma and adenomyoepithelioma. Foote and Frazell [49] proposed the currently accepted term adenoid cystic carcinoma in their classic paper in 1953 and in their fascicle on major salivary gland tumors in 1954.

\subsubsection{Clinical Features}

Adenoid cystic carcinoma occurs in adults between 50 and 70 years of age with equal prevalence in males and females [61]. The most frequent locations of this tumor are the parotid, submandibular, and palatal salivary glands [62]. They are only rarely observed in the sublingual gland [61].

Clinically adenoid cystic carcinoma manifests in the major and intraoral accessory salivary glands as a slowgrowing swelling or mass. Pain and fixation to skin as well as surrounding deeper structures generally occur during the course of tumor growth. An ominous feature of adenoid cystic carcinoma of the parotid gland is paralysis of the facial nerve. Radiographic examination is valuable in assessing the extent of osseous destruction. Symptoms may have been present for months or years and are generally of longer duration than those associated with squamous carcinoma, which is the most frequent malignancy of this location. Adenoid cystic carcinomas of the maxillary antrum, nasal cavity, and ear canal produce symptoms of pain, obstruction, and deafness, respectively.

Histopathologically, ACC are classified into cribriform pattern, tubular pattern, and solid pattern. A major microscopic feature in most adenoid cystic carcinomas is the propensity for the tumor to involve peripheral nerves, reported to occur in $20-80 \%$ of the patients. Although perineural invasion is characteristic of adenoid cystic carcinoma, it is not unique to the tumor. 


\subsubsection{Management of Adenoid Cystic Carcinoma}

Complete excision like all other tumors is the treatment of choice. Elective regional lymph node dissection is not indicated, because distant metastasis is more common than cervical (regional) node involvement. According to Maciejewski et al., radical surgical excision with histologically proven negative margins with postoperative radiotherapy for all cases should be the treatment of choice. Lymph node dissection is recommended only in cases of histologically proven positive lymph nodes [60]. A frozen section diagnosis to achieve tumor-free safe margins is necessary to specifically look for safe perineural margins because ACC is known to spread quickly along the nerve.

The slow biologic growth of adenoid cystic carcinoma along with a late metastasis of the disease results in relatively favorable 5-year survival rates. Factors that indicate a poor prognosis include failure to achieve clear margins at first surgery, a solid pattern histologically, recurrent disease, and distant metastasis [63].

In a study by Witten et al., local recurrences have been seen in almost $32 \%$ of the cases [63]. The risk of distant metastasis is also high, approximately $40 \%$, and can occur in less than 8 years after treatment.

\subsubsection{Clear Cell Carcinoma}

Clear cell neoplasms of salivary glands have been classified as both adenomas and carcinomas [64].

\subsubsection{Clinical Features}

It occurs predominantly in the palatal minor salivary glands followed by parotid and submandibular glands without any sexual or racial predilection. It occurs between the ages of 18 and 86 years, mean 56 years. Clinical manifestation is of a swelling similar to other tumors. It may be confused with mucoepidermoid and acinic cell carcinoma as well as metastatic renal cell carcinoma. A positive reaction to mucicarmine would preclude the possibility of renal cell carcinoma.

\subsubsection{Management}

Due to their infiltrative growth and the incidence of recurrence and regional lymph node metastases, it is appropriate to consider them low-grade adenocarcinomas. Hence surgical treatment is the mainstay of management.

\subsubsection{Epithelial-Myoepithelial Carcinoma}

The epithelial-myoepithelial carcinoma of intercalated duct origin is a rare biphasic type of low-grade salivary gland car- cinoma that constitutes less than $1 \%$ of salivary gland neoplasms.

\subsubsection{Clinical Features}

It occurs more commonly in females around 60-70 years of age. Parotid gland is the most frequently affected [65]. Patients present with an asymptomatic or painful salivary gland swelling with a history of steady increase in size over an extended period of time and may also present with facial paralysis [66]. In patients with maxillary involvement, nasal obstruction and facial deformity may be the presenting complaints. Differential diagnosis includes pleomorphic adenoma, acinic cell adenocarcinoma, adenoid cystic carcinoma, mucoepidermoid carcinoma, sebaceous carcinoma, and oncocytoma.

\subsubsection{Management}

Surgery is considered the primary mode of treatment. Total parotidectomy with facial nerve preservation is advocated for tumors in the parotid gland unless the nerve is involved by the tumor. Recurrences and distant metastasis are a known complication.

\subsubsection{Carcinosarcoma}

Carcinosarcoma, also known as true malignant mixed tumor, shows malignant cells in both the stromal and epithelial components [67]. When these tumors metastasize, both components metastasize together.

\subsubsection{Clinical Features}

Carcinosarcomas are rare tumors with an average incidence of $0.4 \%$ in major salivary glands and $1 \%$ in minor salivary glands. It occurs between 25 and 85 years of age (average 58.5 years) with the frequency of occurrence being more in parotid than submandibular gland and then minor glands in palate and tongue [67].

It presents as an enlarging mass with a rapid increase in size and may be associated with pain and facial nerve paralysis. Rarely, patients present with metastases or experience difficulty in swallowing or breathing. A patient with a central nervous system metastasis has been reported to present with headaches [67].

\subsubsection{Management}

The data available is insufficient to recommend one type of therapy as definitive. However radical surgical excision, together with radiation therapy and lymph node dissection for palpable disease, seems to be the most prudent form of therapy. Radiotherapy as the only means of therapy has not proved effective. Tumor metastasis is most frequent to the lungs followed by hilar and cervical lymph nodes. Distant metastasis is also rarely found [67]. 


\subsubsection{Undifferentiated Carcinomas}

This group includes three distinct entities:

1. Lymphoepithelial carcinomas (malignant lymphoepithelial lesion): It is more prevalent in females and occurs between fourth and fifth decade of life. The parotid gland is most commonly involved followed by submandibular gland. Painful indurated mass and occasional facial paralysis are the presenting symptoms. It might be preceded by benign lymphoepithelial lesion for many years. It is managed by wide surgical excision with or without neck dissection and may be supplemented with radiotherapy.

2. Undifferentiated large cell carcinomas: It occurs predominantly in older population with a male predilection. It most commonly affects the parotid followed by submandibular and minor salivary glands. Histologically it shows predominantly poorly differentiated large cell components. It carries a poor prognosis and has a higher risk of locoregional as well as distant metastasis and recurrences. The worst prognostic factor is the size of the lesion. Less than $4 \mathrm{~cm}$, mean survival time was 46 months, and more than $4 \mathrm{~cm}$ it was reduced to 7.7 months [51].

3. Undifferentiated small cell carcinomas: It rarely affects the salivary glands and is primarily a pulmonary tumor. When it occurs, it shows a male preponderance and occurs between fifth and seventh decade, in the parotid mainly followed by submandibular gland. It presents as a rapidly growing mass which may or may not be painful. Management is primarily wide surgical excision with neck dissection for clinically positive neck node involvement. Chemoradiotherapy may be used as an adjunctive modality for treatment. It tends to metastasize via the hematogenous route, and hence a distant metastasis needs to be ruled out.

\subsubsection{Squamous Cell Carcinoma}

The diagnosis of primary squamous cell carcinoma is limited to the major glands because distinction between possible minor salivary gland primary tumors and those originating from mucosal surface epithelium is generally not possible.

\subsubsection{Clinical Features}

It occurs between 7 and 95 years of age, the mean age being 60.5 years with a male predilection of $2: 1$. Parotid gland is the most commonly involved followed by submandibular and sublingual glands [68]. It presents as an asymptomatic mass with occasional pain and facial nerve palsy. This tumor often replaces the entire gland with fixation to underlying structures and skin.

Ductal squamous metaplasia, high-grade mucoepidermoid carcinoma, and lymphoepithelial carcinoma should be considered in the differential diagnosis of squamous cell carcinoma of the salivary gland.

\subsubsection{Management}

Surgical management is the mainstay of treatment. Parotidectomy with or without facial nerve preservation depending on the case is needed for parotid tumors. Submandibular sialadenectomy is needed for submandibular gland tumors. A neck dissection is done in clinically positive necks at the slightest suspicion. Locoregional failure is the most significant problem, and hence a composite resection in larger submandibular malignancies might be needed. Postoperative radiotherapy when combined with surgery may improve the locoregional control [68].

\subsection{Surgical Management of Parotid Tumors (Video 46.3)}

The following procedures are performed:

- Local excision of the parotid gland

- Superficial parotidectomy

- Functional superficial parotidectomy

- Complete parotidectomy with facial nerve preservation

- Radical parotidectomy with or without neck dissection

- Parotidomandibulectomy

- Temporoparotidectomy

\subsubsection{Skin Incisions for Parotidectomy [69]}

The ideal incision should combine good exposure with the best ultimate cosmetic result. This part of the procedure is common to all the resection procedures unless skin is being excised because it is involved by the tumor.

Gutierrez (1903) - The incision had a temporal extension, a preauricular component, and a limb extending onto the neck in one of the skin creases (Fig. 46.22). The chief drawback of this incisions was esthetics in case of development of a keloid.

Redon and Vaillant and Laudenbach-The incision line is similar to that proposed by Adson (Fig. 46.23).

Adson and Ott have described a "Y"-shaped incision with a preauricular part, a postauricular part, and a cervical incision line that splits off from the site of union of the first two branches (Fig. 46.24). The advantage of this incision is improved esthetics because it lacks a temporal incision line, but the drawback is that it impairs dissection. Also, one section of the incision is located in the carotid region.

Samengo (1961) - The incision has a preauricular, a postauricular, and a neck extension in the incision line (Fig. 46.25). 


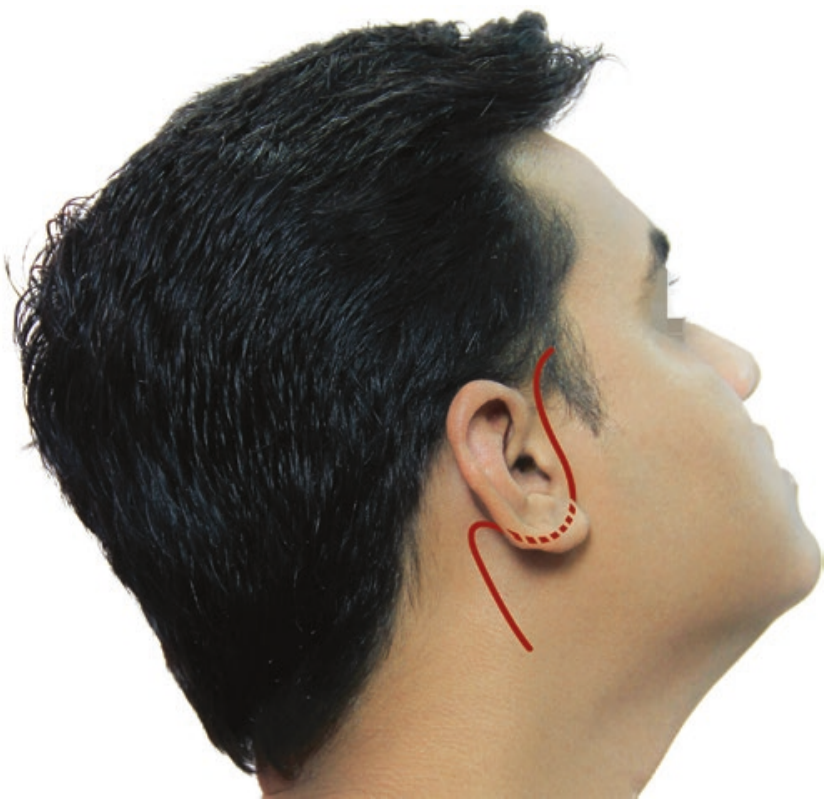

CAssociation of Oral and Maxillofacial Surgeons of India

Fig. 46.22 Gutierrez incision

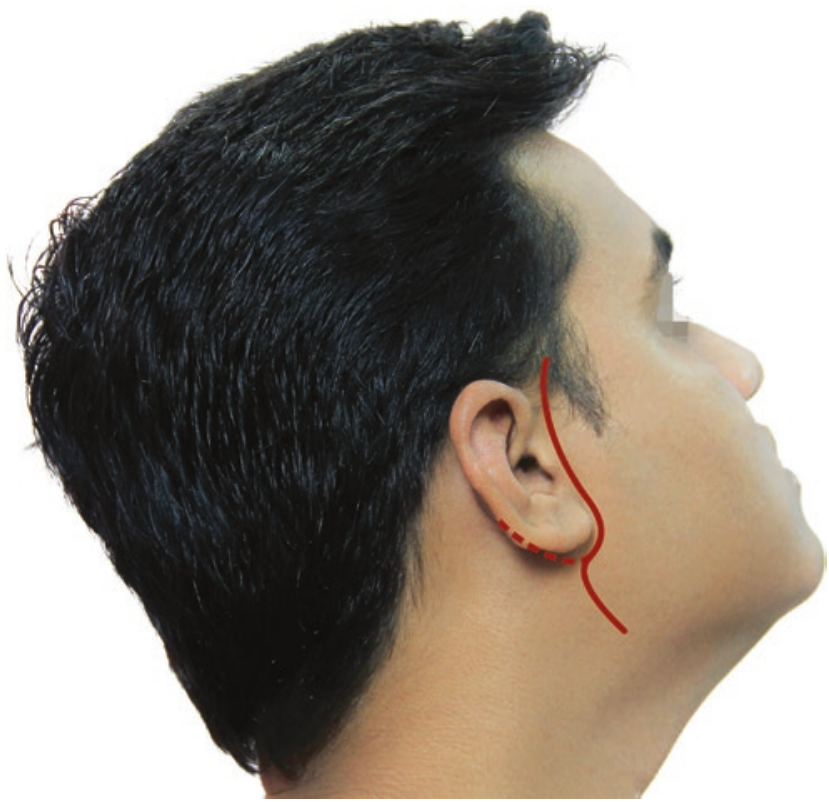

CAssociation of Oral and Maxillofacial Surgeons of India

Fig. 46.24 Adson and Ott incision

Appiani (1967)—The incision within the lower portion of the scalp is hidden by the hair instead of the vertical incision line. The benefit of this incision is better esthetics. However, the temporal extension of this incision is short, and this impairs access to the anterior portion of the gland (Fig. 46.26).

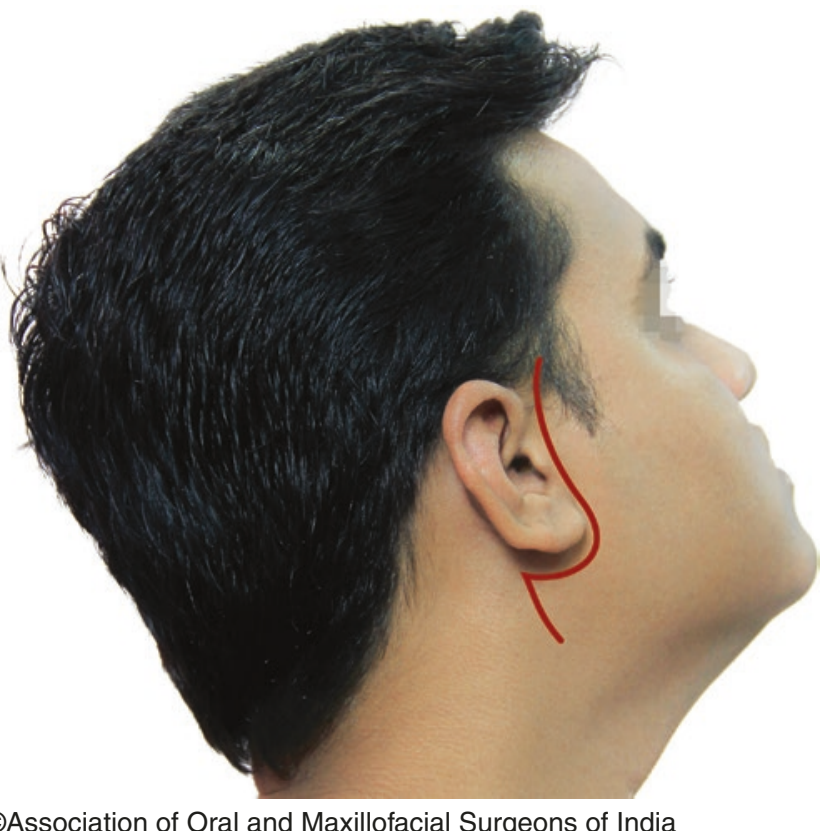

Fig. 46.23 Redon and Valliant and Laudenbach incision

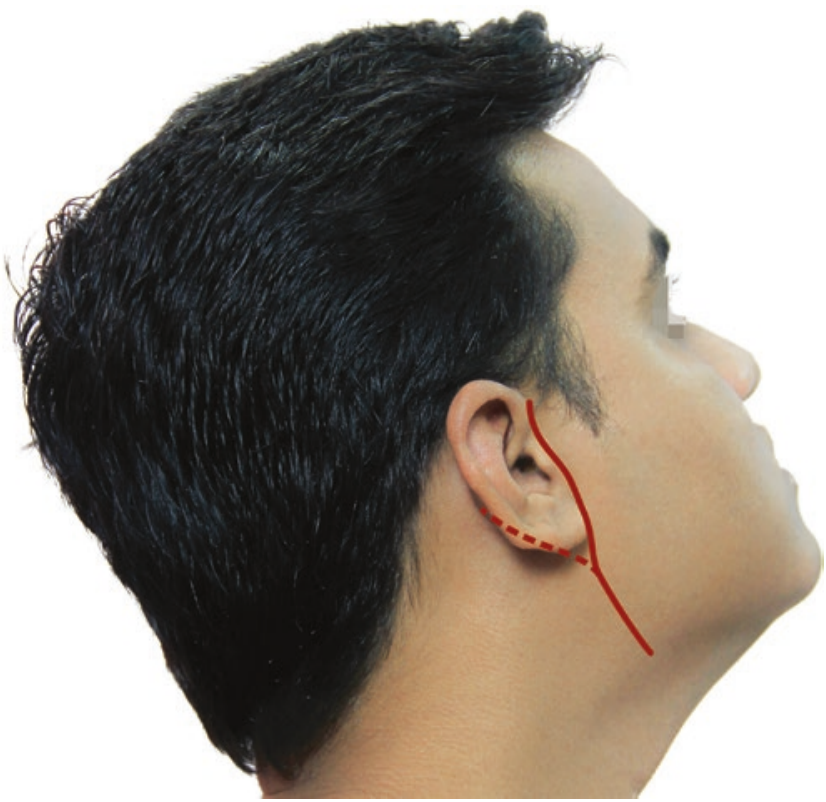

CAssociation of Oral and Maxillofacial Surgeons of India

Fig.46.25 Samengo incision

Ferreria JL et al. [69] modified Appiani's incision by extending the temporal incision line but not beyond the hairline. It provides a better access to the anterior portion of the parotid gland without compromising esthetics. Also, the angles are rounded off where the incision line changes direction reducing dehiscence and salivary fistula formation. 


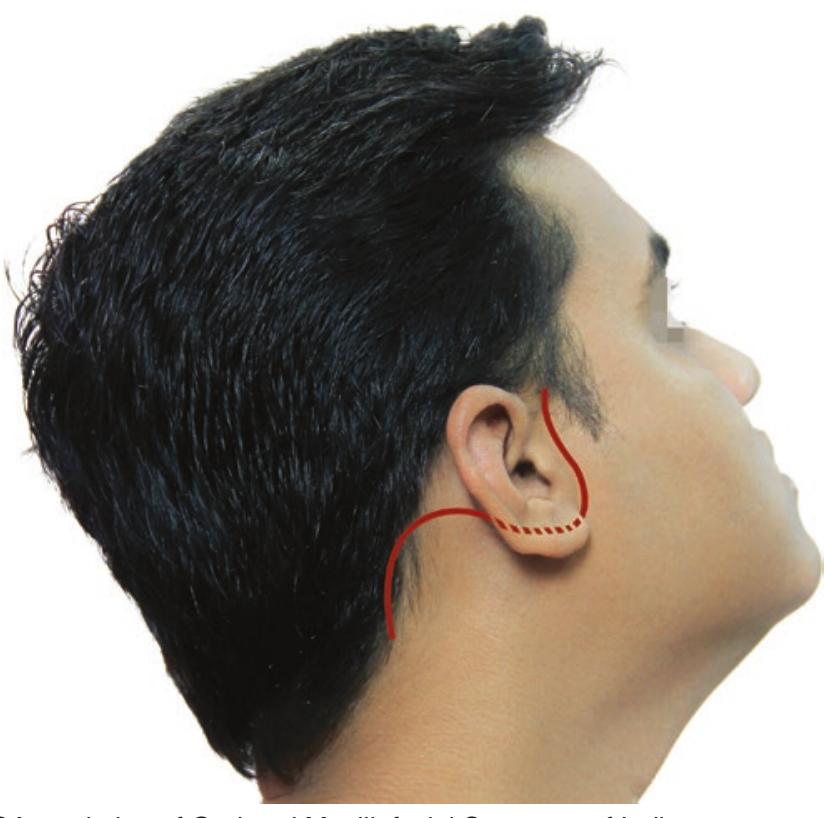

CAssociation of Oral and Maxillofacial Surgeons of India

Fig. 46.26 Appiani's incision

Farrior et al. recommended a single curved incision $1.5-2.0 \mathrm{~cm}$ below the mandible and extending over the mastoid region $1.5 \mathrm{~cm}$ behind the postauricular crease in children. The preauricular crease used in adults is avoided because of the superficial location of the facial nerve and possibility of facial nerve damage during flap elevation [68] (Fig. 46.27).

The Blair incision is an S-shaped incision that starts from the preauricular region and extends in the neck. The major disadvantage of the Blair incision is a visible scar in the neck that may cause facial or cervical disfigurement causing patients dissatisfaction [70].

The standard incision is a modified Blair incision (Fig. 46.28) wherein the skin incision is placed in a preauricular crease and doesn't extend beyond the level of the root of the helix. It extends inferiorly around the ear lobule over the mastoid tip. It gently curves down along the sternocleidomastoid muscle and then slightly forward in a natural crease in the upper neck [71].

A facelift incision can be used to avoid the hollowing after parotidectomy, and the defect can be filled with SMAS advancement flap (Bananno and Casson [72], 1992). However, the SMAS-lifting technique is not a routine procedure for many surgeons [73].

Rai A et al. [74] advocated use of posterior belly of the diagastric muscle flap (PBDMF) for reconstruction of the surgical defect after superficial parotidectomy. PBDM inserts very close to stylomastoid foramen, and it is considered as an

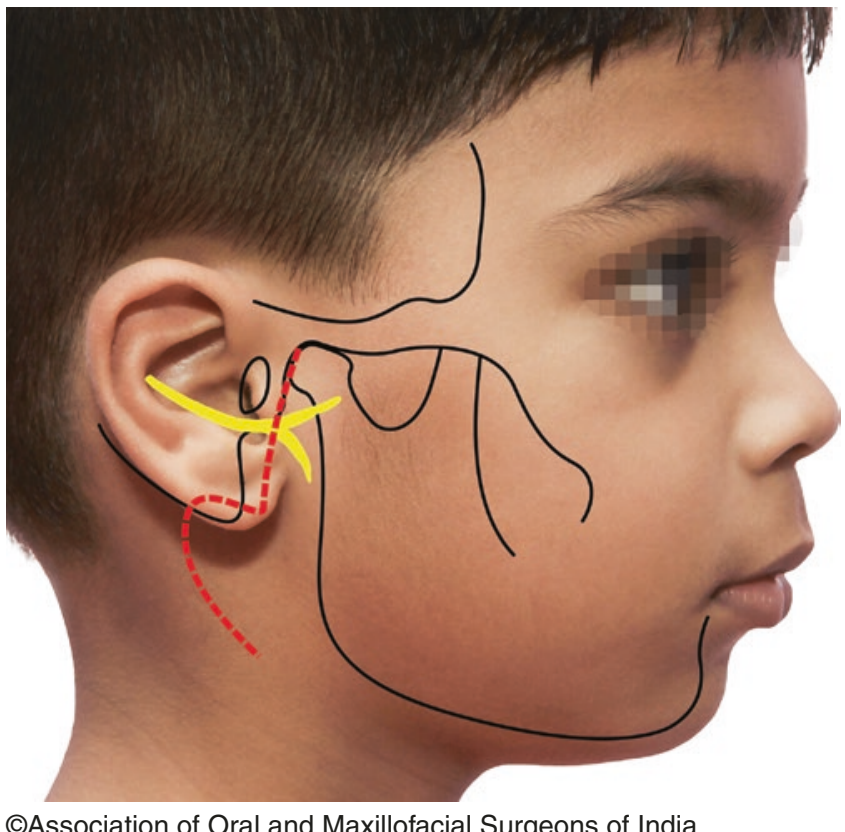

CAssociation of Oral and Maxillofacial Surgeons of India

Fig. 46.27 Modified Blair incision in pediatric patient

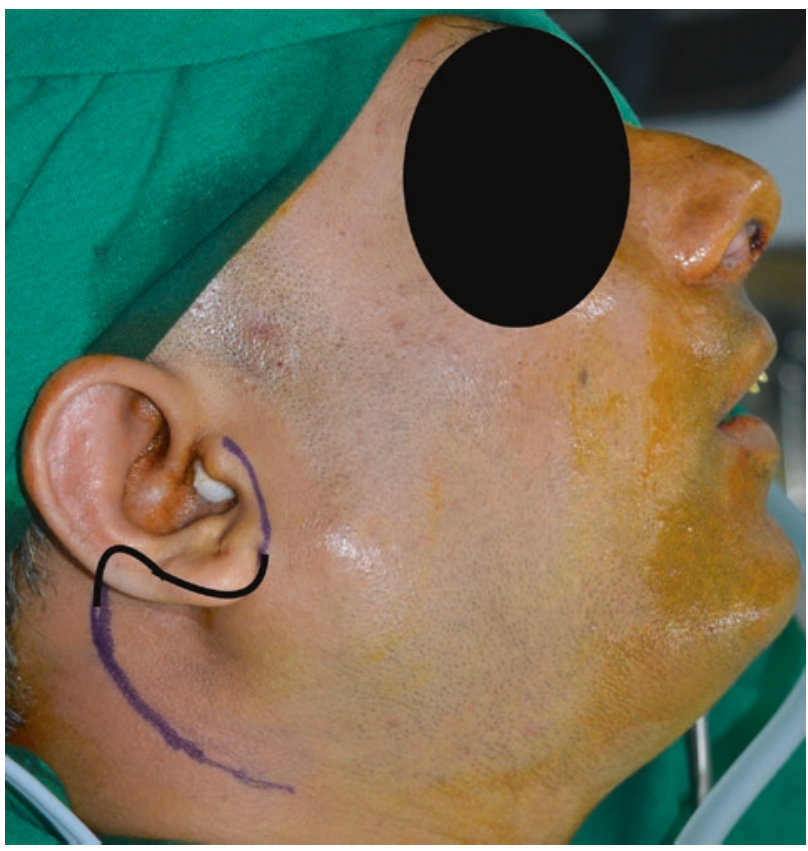

CAssociation of Oral and Maxillofacial Surgeons of India

Fig. 46.28 Modified Blair incision in adults

important landmark in the identification of facial nerve main trunk. The harvesting and dissection of PBDMF becomes easier as it lies in the surgical site, and no extra incision is required to harvest it. It can be used in thin and young patients with good esthetic results. 


\subsubsection{Identification of the Facial Nerve}

This has been previously described in the section on applied anatomy of the parotid gland.

\subsubsection{Surgical Management}

The selection of type of procedure for surgical management of parotid tumors depends on the site, size and clinicohistopathologic features. The various procedures are described briefly as under:

\subsubsection{Local Excision of Parotid Gland}

This technique is used for management of a small tumor in the tail of the parotid gland less than $3.5 \mathrm{~cm}$. Due to small tumor size, most of the functional gland along with the duct can be preserved.

\subsubsection{Parotidectomy with Preservation of the Facial Nerve [75]}

After marking the incision, infiltration is usually done with Saline Plus 1 in 200,000 parts adrenaline instead of lignocaine with adrenaline to avoid blocking the facial nerve fibers. In case lignocaine is used, care should be taken to avoid deep injections. Care should be taken to avoid extending the incision too far posterior beneath the ear lobe to avoid persistent edema [75].

The incision in the neck crease is deepened to raise a flap in the subplatysmal plane (Fig. 46.29). The greater auricular nerve is identified and preserved. It branches over the surface of the gland where two or more branches should be followed and then divided.

Once the deep fascia has been identified, rest of the wound is deepened to this level and skin reflected forward from it. At the zygomatic bone, some subcutaneous fat should be left on the fascia to avoid damaging the branches of facial nerve which lie more superficially as they emerge from the upper part of the parotid. The main trunk of the nerve is found by first separating the lower pole of the gland from the anterior border of the sternomastoid and then from the mastoid process and the cartilaginous part of the external auditory meatus (Fig. 46.30). The wound is deepened anterior to the margin of the sternomastoid, and the lower pole is dissected free as far forward as the external jugular, uncovering the posterior belly of the digastric muscle. The vein should not be divided and tied at this stage because this will increase the venous engorgement of the parotid and the ooze from its divided tissues.

Neither should the lower pole be raised further forward because the branches of the facial nerve often pass superficial to the vein and emerge from the gland anterior to it. The parotid is retracted forward as the dissection proceeds and

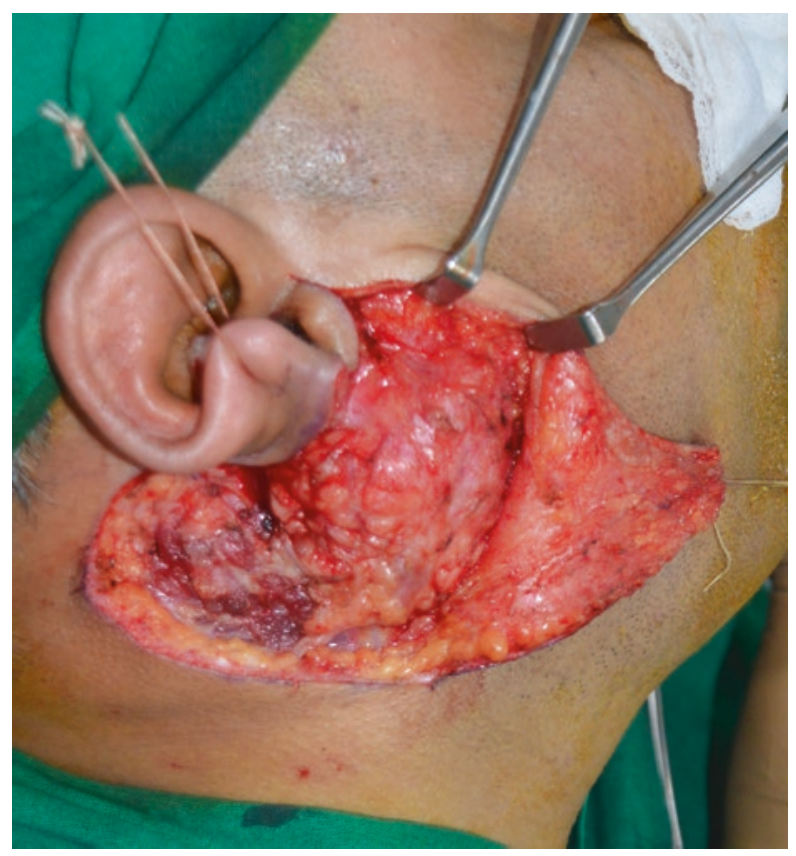

CAssociation of Oral and Maxillofacial Surgeons of India

Fig. 46.29 Flap raised in the sub platysmal plane exposing the superficial surface of tumor

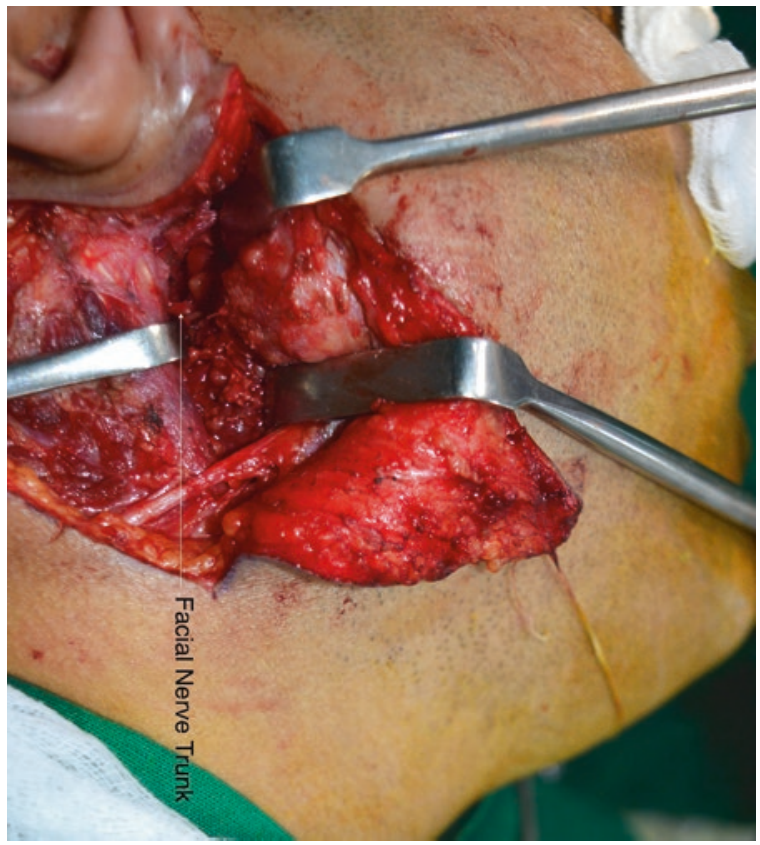

CAssociation of Oral and Maxillofacial Surgeons of India

Fig.46.30 Representing facial nerve main trunk

the pointed, lower extremity of the tragal cartilage (pointer) will be uncovered. Where possible, the edge of the fascia should be raised and the underlying tissue separated by blunt dissection until the nerve is seen as white cords some $2-3 \mathrm{~mm}$ thick. 
The stylomastoid branch of the posterior auricular artery passes superficial to the nerve to enter the stylomastoid foramen. Damage to this vessel should be avoided as bleeding may hamper vision, and also it supplies a nutrient branch to the nerve. The curved mosquito forceps are used for dissection by opening the blades a little at a time to stretch the tissues and raise it, so as to lift the gland substance off the surface of the nerve, and then expose it by cutting through the gland with scissors. At all times when a cut is made, the adjacent nerve must be seen clearly.

Almost immediately the nerve trunk starts to travel laterally within the parotid, and just below the neck of the condyle, it splits into an upper temporofacial and a lower cervicofacial division. Follow the lower division first, and trace the cervical or the marginal mandibular branch anteriorly to a point in front of the parotid to mobilize the lower pole completely. Then by progressing upward, branch by branch further mobilization can be achieved (Fig. 46.31). Some tissue should always be left on the tumor to ensure complete removal.

In general, the nerves pass superficial to the retromandibular vein, but some may pass deep to it. Careful mobilization of both nerve and vein with division and ligation of the latter is necessary. Tiny vessels should be sealed with bipolar diathermy avoiding damage to adjacent nerves.

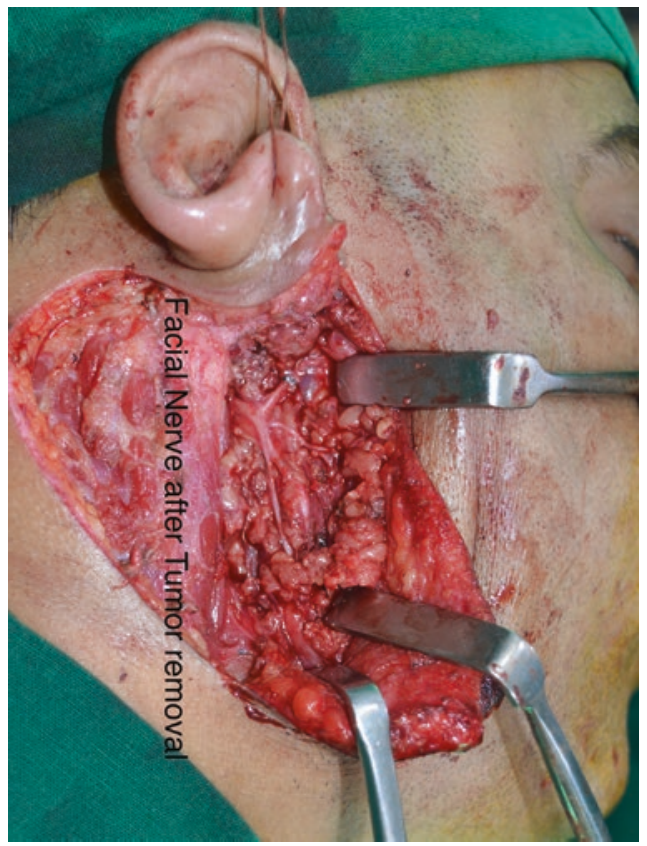

CAssociation of Oral and Maxillofacial Surgeons of India

Fig. 46.31 Parotidectomy with preservation of the facial nerve

\subsubsection{Functional Superficial Parotidectomy} [76]

This is superficial parotidectomy where gland function is preserved by preservation of the Stenson's duct. If the duct is superficial to the buccal branch, its preservation is contraindicated as it will obstruct the surgical procedure. After raising the skin flap and exposing the parotid gland, the duct is identified passing on the masseter muscle. Stenson's duct is located; dissection and ligation of the duct are avoided unless it is located superficial to the buccal branches of the facial nerve. Rest of the procedure is similar to superficial parotidectomy.

\section{Advantages}

- It is a simpler surgery than conservative superficial parotidectomy.

- It preserves partial function of the parotid gland.

- It avoids the influence of subsequent gland atrophy on facial contour.

It decreases postoperative complications.

\subsubsection{Partial Superficial Parotidectomy}

This is similar to local excision of parotid gland. Maximum healthy tissue is left behind without compromising on the clearance. The advantage of this procedure over superficial parotidectomy is relatively low incidence of Frey's syndrome. The reported incidence of this complication is $4.8 \%$ [77]. In addition, better gland function is preserved due to more parenchyma that is left back [78].

\subsubsection{Intraoral Deep Lobe Tumor Excision [79]}

It is a transoral approach used in removal of few benign tumors of the deep lobe, which are easily visible displacing the superior portion of the tonsil and soft palate medially. An incision is made with cautery or knife over the most prominent aspect of the swelling in the tonsil and palate area, extending above and below the apparent location of the tumor. The constrictor muscle is identified, and dissection is continued through thinned constrictor muscle by dividing it above and below the tumor. Pressure on the neck often assists in removal of the tumor. Fascial connections from the tumor into the adjacent bed are removed with blunt dissection, and the tumor is delivered into the mouth. Any vascular connections to the tumor should be cauterized, and meticulous hemostasis should be achieved. The superior and inferior portions of the wound are closed with interrupted sutures. The middle portion of the wound is left open to heal secondarily. 


\section{Complications}

- Tumor rupture

- Incomplete removal

- Uncontrolled hemorrhage

\subsubsection{Total Parotidectomy with or Without Facial Nerve Preservation}

It is usually indicated in tumors affecting the deep lobe. A neoplasm of the deep part of the parotid enters the soft palate through the interval between the styloid process and the back of the mandible and is often of dumbbell shape with the isthmus lying in this gap. After raising a skin flap, the facial nerve is identified and dissected out leaving a layer of glandular tissue on it. An access osteotomy either in the form of vertical subsigmoid or mandibular body distal to the mental foramen is used to open up the interval between the mandible and the styloid process through which the tumor has passed. The stylohyoid muscle may be divided close to the styloid process and turned forward. The external carotid artery will be encountered emerging above the muscles and should be divided. The origin of the facial artery should be identified to check the identity of the vessel.

As the parotid gland and the tumor are freed, it may be raised up between the two nerve bundles or below both bundles. Next entry is made intraorally over the tumor, and under direct vision tissues are divided to deliver the mass. Care is taken to avoid damaging the internal jugular vein and internal carotid artery which lie deep to styloid process. Following removal of the mass, the wound is irrigated, and the oral tissues closed with care using resorbable suture. The drapes are replaced over the mouth, gloves changed, and the mandibular fragments fixed together and the wound closed in the normal way.

\subsubsection{Parotidectomy Using SMAS Plane for Dissection [73]}

The advantages of this flap are that exposure of the gland is sufficient and the dissection is easy to perform. There is no donor-site morbidity, minimum additional operating time, and no extra cost. It seems to decrease the incidence of Frey's syndrome. The speed of the recovery of the facial nerve has been highlighted in the literature. It is more satisfactory from the patient's point of view.

\subsubsection{Parotidomandibulectomy and Temporoparotidectomy [80]}

Parotidomandibulectomy is indicated where there is invasion of the mandible by a malignant neoplasm.

In temporoparatidectomy, small-scale resection of the external auditory canal may be included with the excision of the pinna and overlying skin of the parotid where these structures are involved. The deficiency may be made good with a deltopectoral or other suitable flap.

\subsubsection{Parotidectomy in Continuity with Neck Dissection}

In the case of lymph node metastasis as stated in surgical pathology, neck dissection can be done in continuity with parotidectomy by increasing the neck skin crease incision and clearing the lymphatic structures.

\subsubsection{Complications of Parotid Surgery}

- Facial paresis or paralysis often results from poor technique and failure to preserve small nerve branches.

- Bleeding and hematoma formation, which can significantly compromise the airway.

- Rarely, persistent salivary leakage or sialocele formation occurs.

- Frey's syndrome.

- Skin flap necrosis.

\subsection{Surgical Management of Submandibular and Sublingual Gland Tumors}

Small tumors confined to the gland are treated by sialadenectomy, and tumors spreading beyond the confines of the gland are treated with a wider en bloc excision, which may include resection of the floor of mouth and mandible depending on extent of tumor. The neurotropic tumors might involve the lingual, hypoglossal, mylohyoid, and marginal mandibular nerve leading to a perineurial spread which can be confirmed on frozen section. Thickening and nodularity of the nerves may indicate perineural involvement [81].

\subsubsection{Incision}

For submandibular sialadenectomy, a skin crease incision below $3 \mathrm{~cm}$ from the lower border of mandible is taken to avoid damaging the marginal mandibular nerve which loops below the lower border of the mandible (Fig. 46.32).

For simple excision of the sublingual gland, an incision is made in the floor of the mouth lateral to the submandibular 


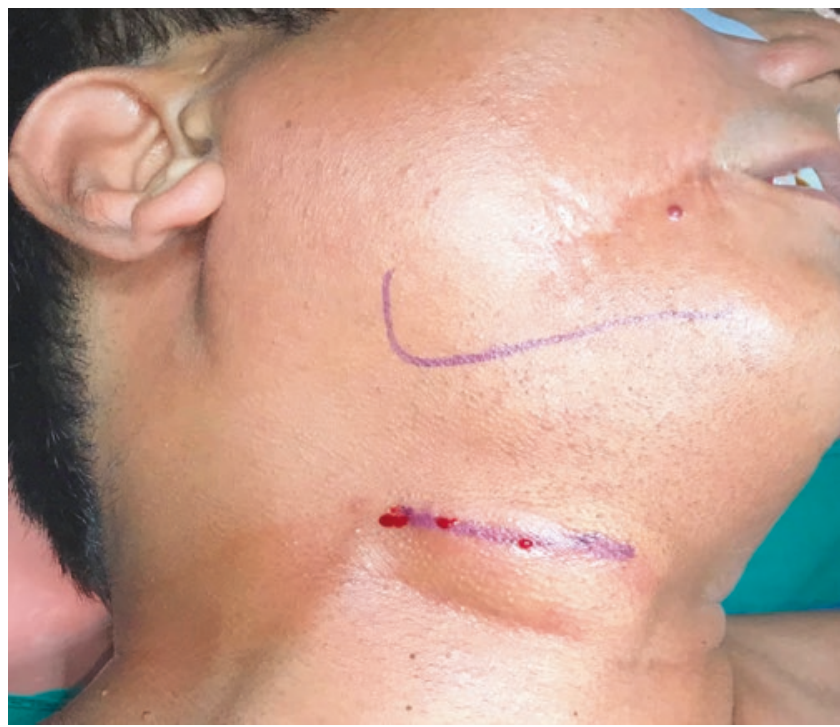

CAssociation of Oral and Maxillofacial Surgeons of India

Fig. 46.32 Submandibular incision

duct taking care to limit it up to premolar region, as at the molar region, there is a chance to damage the lingual nerve. When sublingual gland excision is necessary for a tumor, it should be removed with a wide margin including a rim resection of the mandible.

\subsubsection{Extracapsular Excision of the Submandibular Salivary Gland [82]}

After making an incision in the neck crease, skin flap is raised in the subplatysmal plane (Fig. 46.33). The capsule of the gland should be left intact when the sialadenectomy is being done for a tumor, which might compromise the marginal mandibular nerve. The facial artery and nerve are identified as close to the gland as possible. After transection, they are elevated superiorly to identify and reflect the marginal mandibular nerve. Nowadays the facial artery is spared during surgery to allow free flap anastomosis during oncosurgeries (Fig. 46.34). The investing fascia is then divided at the lower border of mandible, and the gland is delivered out from between the anterior and posterior bellies of the digastric muscle. Anteriorly the gland is separated from the mylohyoid muscle, and lingual nerve, hypoglossal nerve, and Wharton's duct are identified. The lingual nerve shares the same facial sheath as the gland at the upper pole. This attachment of the lingual nerve to the gland represents its parasympathetic supply. The Wharton's duct is inferior to lingual nerve and is often surrounded by sublingual glands. As fascia and gland are mobilized upward from the surface of the hyoglossus, the hypoglossal nerve is identified more inferiorly. It is accompanied by ranine vein. Posteriorly the angular tract

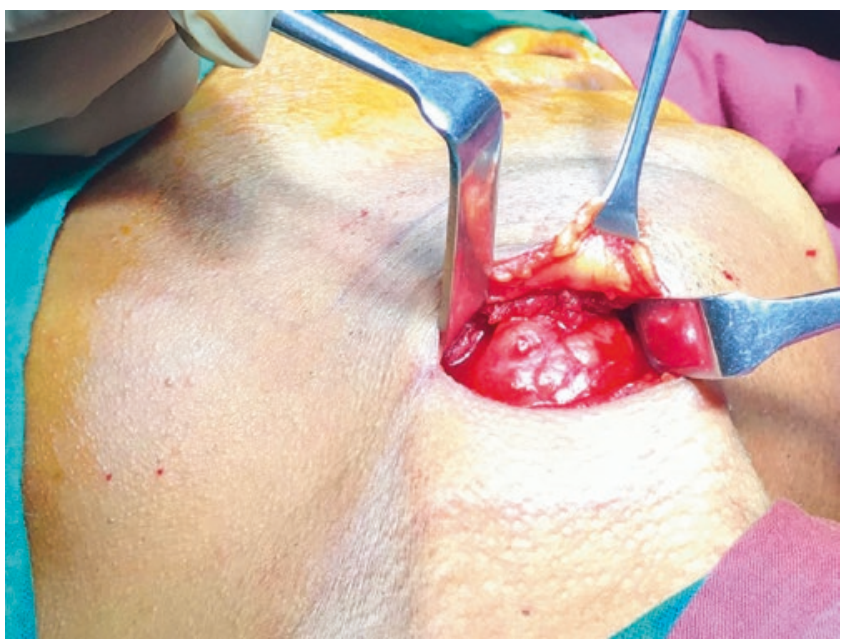

CAssociation of Oral and Maxillofacial Surgeons of India

Fig. 46.33 Submandibular gland exposure with subplatysmal dissection

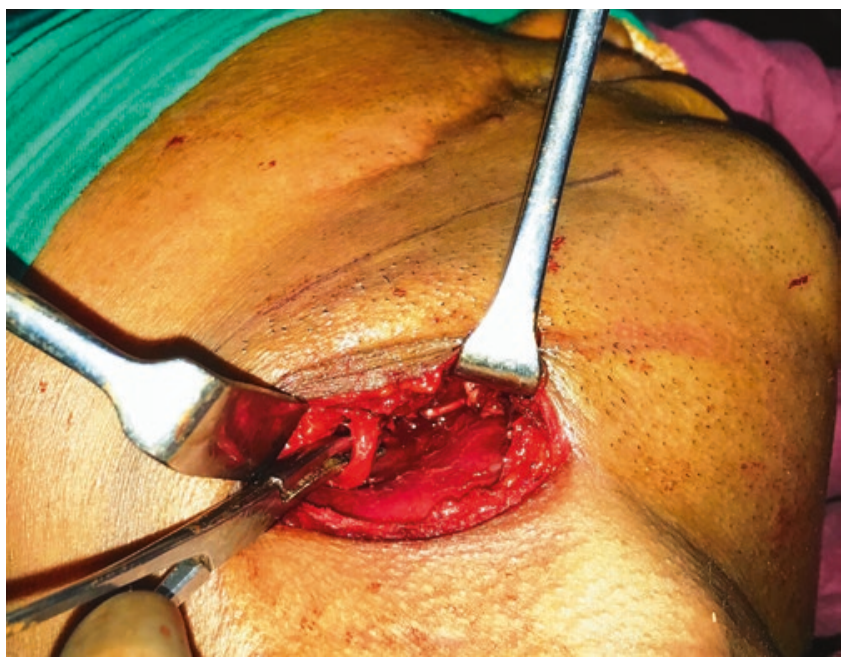

CAssociation of Oral and Maxillofacial Surgeons of India

Fig. 46.34 Facial artery preservation in submandibular sialadenectomy

of fascia has to be cut with scissors to allow the gland in its fascial envelope to be drawn down without grasping the gland with instruments. Where necessary the upper pole may be mobilized via the mouth. An assistant can then depress the gland toward the submandibular wound to enable the operation to be concluded.

The duct and the branch of the lingual nerve supplying the submandibular gland are ligated and transected. The duct is divided close behind the papilla. During excision for inflammatory disease, the nerve is always separated from the gland with knife or scissors. However, if the nerve appears to be involved in a tumor, it is sectioned in front of and behind the gland and the cut ends sutured. The wound is closed in layers with drainage in the usual way. 


\subsection{Management of Minor Salivary Gland Tumors}

Surgical resection of minor salivary gland tumors depends on the site of origin and extent of disease. This may range from a wide local excision of localized low-grade tumors to more radical excision, including marginal or segmental mandibulectomy and/or partial or total resection of the hard or soft palate, partial or total maxillectomy, infratemporal fossa dissection, and/or anterior craniofacial resection for larger and/or high-grade tumors. The V2 and V3 divisions of the trigeminal nerve are at potential risk for perineural spread of minor salivary gland malignancy and may facilitate an early skull base metastasis. Resection of the cranial base may be required in some cases to eradicate the tumor and obtain negative surgical margins [81].

\subsubsection{Excision of Palatal Pleomorphic Adenomas [83]}

Small pleomorphic adenomas on the palate can cause pressure resorption of the bone but do not cause true bony invasion. They are managed by local excision along with the periosteum. In the case of involvement of greater palatine foramen area, the lesion is freed until it can be drawn down, and the vessels clamped and cauterized under direct vision. If not, the vessel retracts into the canal and causes irritating bleeding. The wound is left to granulate secondarily.
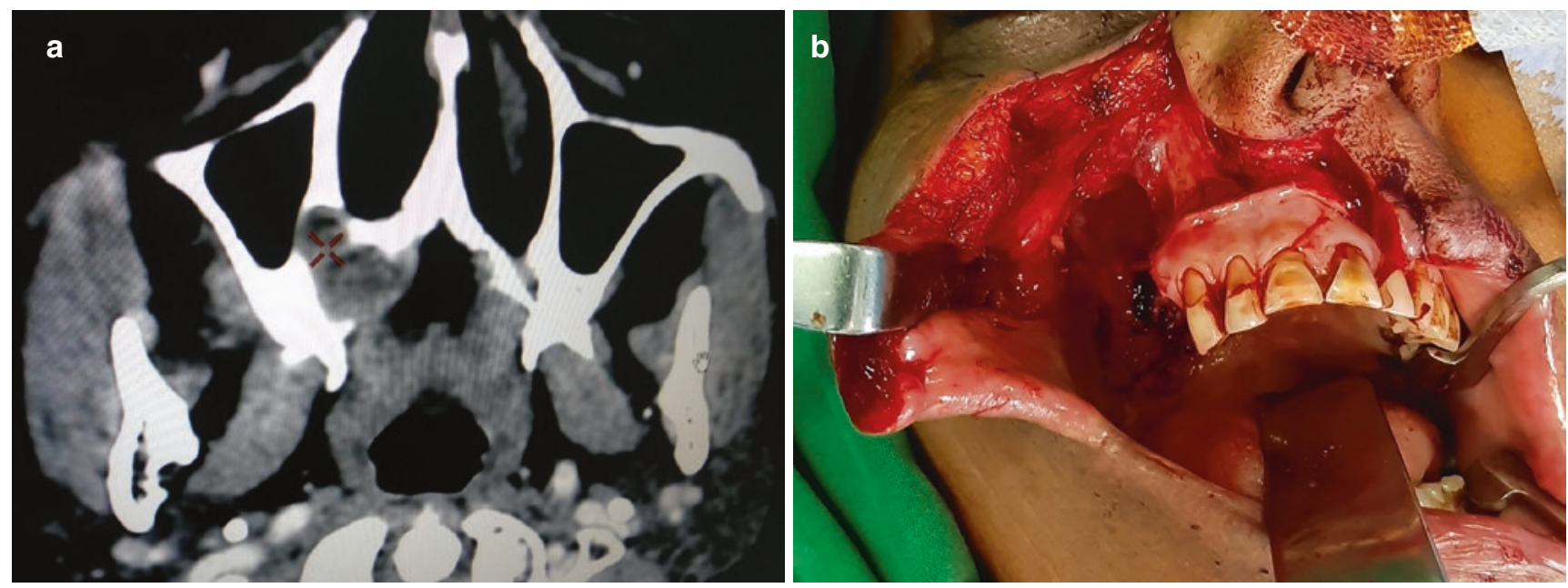

Low-grade mucoepidermoid carcinomas may be treated by the excision of a full-thickness disk of palate, including palatal and alveolar bone. Nasal and oral mucous membranes are sutured together around the defect in the soft palate. Primary reconstruction is avoided and an obturator is used instead (Fig. 46.35a, b).

\subsubsection{Excision of Palatal Adenoid Cystic Carcinoma [83]}

Spread along the perineurial tissues makes an inadequate surgical margin very likely after surgical management of ACC. A combination of surgery and radiotherapy is best. Surgical excision should be generous. Hemimaxillectomy including the orbital floor is a minimum, unless there is very good evidence that less will be sufficient. Where the soft palate and pterygoid region are involved, extended maxillectomy approach is essential to ensure adequate excision under direct vision.

\subsubsection{Excision of Neoplasms of the Cheek and Lips}

A primary excision with a margin of normal adjacent tissue can be used, but if there is any doubt, it can be preceded by a biopsy. Re-operation following incomplete extirpation

CAssociation of Oral and Maxillofacial Surgeons of India

Fig. 46.35 (a) CT scan showing mucoepidermoid carcinoma of palate (red arrow). (b) Surgical excision of tumor using standard Weber-Ferguson incision 
could mean the unnecessary sacrifice of tissue to ensure an adequate margin on the second occasion. Clinically aggressive neoplasms must be biopsied, since adequate treatment may involve radiotherapy and full-thickness excision and repair.

More aggressive tumors affecting the palatal salivary glands are managed by partial maxillectomy or total maxillectomy or extended maxillectomy based on the extent of disease.

\subsubsection{Complications}

- A hematoma may develop in the dead space after gland excision. It can be avoided by meticulous hemostasis and placement of suction drain to clear out any collection. In case a hematoma develops, it can be aspirated or sucked under aseptic precautions. However, it may not be completely effective. The patient can be just put on good antibiotic coverage, and it will resolve without getting infected.

- Trismus occurs due to masseter muscle spasm or inflammation in the TMJ. It generally resolves spontaneously and hence should be just managed symptomatically.

- Salivary fistula occurs uncommonly due to discontinuity between the residual salivary gland parenchyma and the salivary duct. In majority of cases, the problem is selflimiting. Management includes repeated aspiration, pressure dressings, wound care, an antisialogogue medication (glycopyrrolate), and patience.

- Facial nerve dysfunction results from traction injury to the facial nerve (neuropraxia) during dissection in parotid surgery. Complete recovery within a few months can be expected if nerve integrity has been maintained. In case the nerve is transected, it should be followed by immediate nerve grafting repair.

- Auriculotemporal syndrome of Frey is also called gustatory sweating. It manifests as flushing and sweating of the skin of upper cheek, temporal region, and forehead coincident with eating and smelling of food. Following damage to the auriculotemporal nerve or to communicating branches to the facial nerve, secretomotor parasympathetic nerves from the otic ganglion and also sympathetic fibers to the sweat glands traveling in the same nerve are divided. Following regeneration, fibers from otic ganglion come to supply the sweat glands. Minor's starch-iodine test is used for diagnosis [78]. It can be managed by simple treatment of antiperspirant application; $1 \%$ local application of glycopyrrolate is effective. The only effective cure is to divide the parasympathetic fibers from the glossopharyngeal nerve.

Sensory abnormalities associated with greater auricular nerve sacrifice, reflect as sensory deficit in the lower third of pinna including earlobe as well as adjacent preauricular and postauricular skin.

\subsection{Recent Advances [84]}

Robotic sialadenectomy of the submandibular gland has been done via a modified face lift approach. Virgilio et al. performed robotic sialadenectomy of the submandibular gland in five patients (two patients each with sialolithiasis and pleomorphic adenoma and one patient of ranula) with success. They used three robotic arms, two operative arms, and a facedown $30^{\circ}$ endoscopic arm. The operative left arm is equipped with Maryland forceps and right arm with harmonic scalpel.

\subsection{Conclusion}

Salivary gland pathologies may be neoplastic, non-neoplastic, inflammatory, or non-inflammatory. Early surgical intervention after a good clinical, radiological, and histopathological diagnosis is need of an hour to minimize the postoperative complications. Early diagnosis and management with recent advanced technologies is the key factor in achieving excellent prognosis of the disease.

Acknowledgment Author wishes to thank Dr. Anshul Rai for Figs. 46.3, 46.4, 46.9, 46.13, 46.17a, b, and 46.20.

Author wishes to thank Dr. Kedar Saraf, Professor, Dept. of OMDR, SMBT Institute of Dental Sciences, Sangamner, Maharashtra, for Figs. 46.11a, b, and 46.12.

\section{References}

1. Saunders PR, Macpherson DW. Acute suppurative parotitis: a forgotten cause of upper airway obstruction. Oral Surg Oral Med Oral Pathol. 1991;72:412-4.

2. Hollinshead WH. The face. Anatomy for surgeons: Vol I. The head and neck. 3rd ed. Philadelphia: Harper and Row Publishers; 1982. p. 291-324. Chapter 6.

3. Cawson R, Gleeson M. Anatomy and physiology of the salivary glands. In: Gleeson M, editor. Scott-Brown's otolaryngology. Basic sciences. 6th ed. Great Britain: Butterworth Heinemann; 1997. Chapter 9, p. 1/9/1-1/9/18.

4. Snell RS. The head and neck. Clinical anatomy. 7th ed. Philadelphia: Lippincott Williams and Wilkins; 2004, Chapter 11, p. 719-922.

5. McGregor IA, McGregor FM. Salivary glands. Cancer of the face and mouth. Pathology and management for surgeons. Edinburgh: Churchill Livingstone; 1986. Chapter 25, p. 569-606.

6. Rankow RM, Polayes IM. Surgical anatomy and diagnosis. Diseases of Salivary glands. Philadelphia: W.B. Saunders; 1976. Chapter 7, p. 156-84.

7. Borle RM, Jadhav A, Bhola N, Hingnikar P, Gaikwad P. Borle's triangle: a reliable anatomical landmark for ease of identification of facial nerve trunk during parotidectomy. J Oral Biol Craniofac Res. 2019;9(1):33-6. 
8. Wetmore SJ. Surgical landmarks for the facial nerve. Otolaryngol Clin N Am. 1991;24(3):505-30.

9. Farrior JB, Santini H. Facial nerve identification in children. Otolaryngol Head Neck Surg. 1985;93:173.

10. Pather N, Osman M. Landmark of facial nerve: implication for parotidectomy. Surg Radiol Anat. 2006;28(2):170-5.

11. http://apps.who.int/classifications/apps/icd/icd10online2003/fr-icd. htm

12. Norman JE, McGurk M. Salivary gland imaging. In: Morse MH, editor. Color atlas and text of Salivary glands - diseases, disorders and surgery. Wolfe, Spain: Mosby; 1995. p. 105-27.

13. Lowman RM, Cheng GK. Diagnostic roentgenology. In: Rankow RM, Polayes IM, editors. Diseases of salivary glands. Philadelphia: W.B. Saunders; 1976. Chapter 4, p. 54-98.

14. DelBalso A. Salivary imaging. Oral Maxillofac Surg Clin N Am. 1995;7(3):387-422.

15. Taylor \& Francis. Acta Oto-Laryngologica. 1998;118 Suppl $538: 214-20$

16. Kim D, Uy C, Mandel L. Sialosis of unknown origin. N Y State Dent J. 1998;64(7):38-40.

17. McQuone SJ. Acute viral and bacterial infections of the salivary glands. Otolaryngol Clin N Am. 1999;32(5):793-811.

18. Nahlieli O, Bar T, Shacham R. Management of chronic recurrent parotitis: current therapy. J Oral Maxillofac Surg. 2004;62:1150-5.

19. Work WP, Hecht DW. Inflammatory diseases of the major salivary glands. In: Papparella MM, Shumrick DF, editors. Otolaryngology, vol. 3. Philadelphia: WB Saunders; 1980. p. 2235-43.

20. Williams MF. Sialolithiasis. Otolaryngol Clin N Am. 1999;32(5):819-34.

21. Lustmann J, Regev E, Melamed Y. Sialolithiasis: a survey on 245 patients and a review of literature. Int J Oral Maxillofac Surg. 1990;19:135-8.

22. Kawaguchi K, Yamada H, Iida N, Horie A, Sato J, Seto K. Sialodochoplasty to treat sialoliths using a microsurgical technique. Br J Oral Maxillofac Surg. 2008;46(7):607-8.

23. Park JH, Kim JW, Lee YM, Oh CW, Chang HS, Lee SW. Longterm study of sialodochoplasty for preventing submandibular sialolithiasis recurrence. Clin Exp Otorhinolaryngol. 2012;5(1):34-8.

24. Arrieta AJ, McCaffrey TV. Inflammatory disorders of Salivary glands. In: Cummins Otolaryngology - head and neck surgery. 4th ed. Mosby; 2005. Part 5. Chapter 58, p. 1323-38.

25. Agni N, Borle R. Non neoplastic diseases. In: Salivary gland pathologies. Jaypee; 2013. Chapter 7, 54-89.

26. Rice DH. Salivary gland disorders: neoplastic and nonneoplastic. Med Clin N Am. 1999;83(1):197-217.

27. Mandel L. Inflammatory disorders - clinicopathologic considerations. Diseases of salivary glands. In: Rankow RM, Polayes IM, editors. Philadelphia: W.B. Saunders; 1976. Chapter 9, Part 1, p. 202-38.

28. Shafer WG, Hine MK, Levy BM. Tumors of salivary glands. A textbook of oral pathology. 4th ed. Singapore: Harcourt Asia PTE Ltd.; 1993. Chapter 3, p. 231-57.

29. Manoussakis MN, Moutsopoulos HM. Sjögren's syndrome. Otolaryngol Clin N Am. 1999;32(5):843-60.

30. Trott MS, Hughes GB, Calabrese LH. Hearing and Sjögren's syndrome. Ear Nose Throat J. 1996;75:666.

31. Yamasoba T, Tayama N, Syoji M, et al. Clinicostatistical study of lower lip mucoceles. Head Neck. 1990;12:316.

32. Marx DE, Stern D. Non-neoplastic salivary gland disease. In: Oral and maxillofacial pathology: a rationale for diagnosis and treatment. New Delhi: Quintessence Publishing; 2003. Chapter 11, p. 497-527.

33. Huang I, et al. Treatment of mucocele of the lower lip with carbon dioxide laser. J Oral Maxillofac Surg. 2007;65:855-8.

34. Baurmash HD. Mucoceles and ranulas. J Oral Maxillofac Surg. 2003;61:369-78.
35. Harrison JD. Modern management and pathophysiology of ranula: literature review. Head Neck. 2010;32:1310.

36. Kono M, et al. Evaluation of OK-432 injection therapy as possible primary treatment of intraoral ranula. J Oral Maxillofac Surg. 2017;75:336-42.

37. Schneider AB, Favus MJ, Stachura ME, et al. Salivary gland neoplasms as a late consequence of head and neck irradiation. Ann Intern Med. 1977;87(2):160-4.

38. Tsai CC, Chen CL, Hsu HC. Expression of Epstein-Barr virus in carcinomas of major salivary glands: a strong association with lymphoepithelioma-like carcinoma. Hum Pathol. 1996;27(3):258-62.

39. Sadetzki S, Oberman B, Mandelzweig L, et al. Smoking and risk of parotid gland tumors: a nationwide case-control study. Cancer. 2008;112(9):1974-82.

40. Spitz MR, Batsakis JG. Major salivary gland carcinoma. Descriptive epidemiology and survival of 498 patients. Arch Otolaryngol. 1984;110(1):45-9.

41. Van Der Waal I. Salivary gland neoplasms. In: Van Der Waal I, Prabhu SR, Wilson DF, Daftary DK, Johnson NW, editors. Oral diseases in the tropics. Delhi: Oxford University Press; 1993. Chapter 41, p. 478-86.

42. Amin MB, Edge SB, Greene FL, et al., editors. AJCC cancer staging manual. 8th ed. New York: Springer; 2017.

43. Seifert G, Sobin LH. The World Health Organization's histological classification of salivary gland tumors. A commentary on the second edition. Cancer. 1992;70(2):379-85.

44. Seifert G. Diagnosis and prognosis of salivary gland tumors. An interpretation of new revised WHO classification. Mund Kiefer Gesichtschir. 1997;1(5):252-67.

45. Seethala RR, Stenman G. Update from the 4th edition of the World Health Organization classification of head and neck tumours: tumors of the salivary gland. Head Neck Pathol. 2017;11(1):55-67.

46. Ord RA. Surgical management of Parotid tumors. Oral Maxillofac Surg Clin N Am. 1995;7(3):529-64.

47. Cornog JL, Gray SR. Surgical and clinical pathology of salivary gland tumors. In: Rankow RM, Polayes IM, editors. Diseases of salivary glands. Philadelphia: W.B. Saunders; 1976. Chapter 5, p. $99-142$.

48. Waldron CA. Mixed tumor (Pleomorphic adenoma) and Myoepithelioma. In: Ellis GL, editor. Surgical pathology of the salivary glands. Philadelphia: W.B. Saunders; 1991. Chapter 10, p. $165-86$.

49. Foote FW, Frazell EL. Tumours of the major salivary glands. Cancer. 1953;6:1065-133.

50. Papadogeorgakis N, Skouteris CA, Mylonas AI, Angelopoulos AP. Superficial parotidectomy: technical modifications based on tumor characteristics. J Cranio Maxillofac Surg. 2004;32:350-3.

51. Batsakis JG. Tumors of the head and neck - Clinical and pathological considerations. 2nd ed. Baltimore: Williams and Wilkins; 1979. Chapter 1.

52. Warnock GR. Papillary cystadenoma lymphomatosum (Wharton's tumor). In: Ellis GL, editor. Surgical pathology of the salivary glands. Philadelphia: W.B. Saunders; 1991. Chapter 11, p. 187-201.

53. Goode RK. Oncocytoma. In: Ellis GL, editor. Surgical pathology of the salivary glands. Philadelphia: W.B. Saunders; 1991. Chapter 13, p. $225-37$.

54. Kratochvil FJ. Canalicular adenoma and Basal cell adenoma. In: Ellis GL, editor. Surgical pathology of the salivary glands. Philadelphia: W.B. Saunders; 1991. Chapter 12, p. 202-24.

55. Ellis GL, Auclair PL. Ductal papillomas. In: Ellis GL, editor. Surgical pathology of the salivary glands. Philadelphia: W.B. Saunders; 1991. Chapter 14, p. 238-51.

56. White DK, Miller AS, McDaniel RK, Rothman BN. Inverted ductal papilloma: a distinctive lesion of minor salivary gland. Cancer. 1982;49:519-24. 
57. Auclair PL, Ellis GL. Mucoepidermoid carcinoma. Surgical pathology of the salivary glands. Philadelphia: W.B. Saunders; 1991. Chapter 16, p. 269-98.

58. Healey WV, Perzin KH, Smith L. Mucoepidermoid carcinoma of salivary gland origin: classification, clinical-pathologic correlation, and results of treatment. Cancer. 1970;26:368-88.

59. Olsen KD, Devine KD, Weiland LH. Mucoepidermoid carcinoma of the oral cavity. Otolaryngol Head Neck Surg. 1981;89:783-91.

60. Maciejewski A, Szymczyk C, Wierzgon J. Outcome of surgery for adenoid cystic carcinoma of head and neck region. J CranioMaxillofac Surg. 2002;30:59-61.

61. Tomich CE. Adenoid cystic carcinoma. In: Ellis GL, Auclair PL, Gnepp DR, editors. Surgical pathology of the salivary glands. Philadelphia: W.B. Saunders; 1991. Chapter 19, p. 333-49.

62. Kim KH, Sung MW. Adenoid cystic carcinoma of the head and neck. Arch Otolaryngol Head Neck Surg. 1994;120:721-6.

63. Witten J, Hybert F, Hansen HS. Treatment of malignant tumors in the parotid glands. Cancer. 1990;65:2515-20.

64. Auclair PL, Ellis GL. Clear cell carcinoma. In: Ellis GL, Auclair PL, Gnepp DR, editors. Surgical pathology of the salivary glands. Philadelphia: W.B. Saunders; 1991. Chapter 22, p. 379-89.

65. Corio RL. Epithelial - myoepithelial carcinoma. In: Ellis GL, Auclair PL, Gnepp DR, editors. Surgical pathology of the salivary glands. Philadelphia: W.B. Saunders; 1991. Chapter 24, p. 412-21.

66. Corio RL, Sciubba JJ, Brannon RB, Batsakis JG. Epithelialmyoepithelial carcinoma of intercalated duct origin. Oral Surg Oral Med Oral Pathol. 1982;53:280-7.

67. Gnepp D, Wenig B. Malignant mixed tumors. In: Ellis GL, Auclair PL, Gnepp DR, editors. Surgical pathology of the salivary glands. Philadelphia: W.B. Saunders; 1991. Chapter 20. p. 350-68.

68. Speight PM, Barrett AW. Salivary gland tumours. Oral Dis. 2002;8(5):229-40.

69. Ferreria JL, Maurino N, Michael E, Ratinoff M, Rubio E. Surgery of the Parotid region: a new approach. J Oral and Maxillofac Surg. 1990;48:803-7.

70. Blair VP, editor. Surgery and diseases of the mouth and jaw. 3rd ed. St Louis: Mosby; 1918.

71. Hanna EY, Lee S, Fan CY, Suen JY. Benign neoplasms of the salivary glands. In: Haughley $\mathrm{BH}$, editor. Cummings otolaryngology head and neck surgery. vol. II, 4th ed. Elsevier Mosby; 2005. Chapter 60, p. 1348-77.

72. Bananno PC, Casson PR. Frey's syndrome: a preventable phenomenon. Plast Reconstr Surg. 1992;89(3):452-6.

73. Meningaud JP, Bertolus C, Bertrand JC. Parotidectomy: assessment of a surgical technique including facelift incision and SMAS advancement. J Cranio-Maxillofac Surg. 2006;34:34-7.
74. Rai A, et al. Posterior belly of digastric muscle flap for contour deformity correction after superficial parotidectomy. J Stomatol Oral Maxillofac Surg. 2018;119(4):304-6.

75. Johns M, Nachlas N. Salivary gland tumors. In: Paperella M, Shumrick D, Gluckman J, Meyerhoff W, editors. Otolaryngology. vol. 3, 3rd ed. Philadelphia: W.B. Saunders; 1991. Chapter 20, p. 2099-127.

76. Kun Z, Dao-Yi Q, Li-Min W. Functional superficial parotidectomy. J Oral Maxillofac Surg. 1994;52:1038-41.

77. Papadogeorgakis N, Skouteris CA, Mylonas AI, Angelopoulos AP. Superficial parotidectomy: technical modifications based on tumor characteristics. J Cranio Maxillofac Surg. 2004;32:350-3.

78. Yamashita T, Tomoda K, Kumazawa T. The usefulness of partial parotidectomy for benign parotid gland tumors. Acta Otolaryngol. 1993;500:113-6.

79. Oslen KD. Intraoral salivary gland tumor removal. Section I. Head and neck. In: Bailey BJ, Calhoun KH, Friedman NR, Newlands SD, Vrabec JT, editors. Atlas of head and neck surgery - Otolaryngology. 2nd ed. Philadelphia: Lippincott Williams \& Wilkins. p. 6-7.

80. Shah JP. Color atlas of operative techniques in head and neck surgery. England: Wolfe Medical. p. 117-33.

81. Hanna EY, Suen JY. Malignant tumors of the salivary glands. In: Myers EN, Suen JY, Myers JN, Hanna EY, editors. Cancer of the head and neck. 4th ed. Saunders; 2003. Chapter 21, p. 475-510.

82. Seward GR. Nodular enlargement of a salivary gland. In: Moore J, editor. Surgery of the mouth and jaws. London: Blackwell Scientific; 1985. Chapter 38, p. 676-99.

83. Hanna EY, Suen JY. The Parotid neoplasm. Section 22. Controversies in otolaryngology. In: Pensak ML, editor. New York: Publication Thieme; 2001. Chapter 66, p. 348-54.

84. Virgilio DA, et al. Robotic sialoadenectomy of the submandibular gland via a modified face-lift approach. Int J Oral Maxillofac Surg. 2012;41:1325-9.

\section{Additional Reading}

Barnes L, Eveson JW, Reichart P, Sidransky D. World Health Organization classification of tumours. Pathology and genetics of head and neck tumours. vol. 9. Lyon: IARC; 2005.

Kennedy RA. WHO is in and WHO is out of the mouth, salivary glands, and jaws sections of the 4th edition of the WHO classification of head and neck tumours. Br J Oral Maxillofac Surg. 2018;56(2):90-5.

McGurk M, Combes J. Controversies in the management of salivary gland disease. 2nd ed. Oxford University Press; 2013.

Open Access This chapter is licensed under the terms of the Creative Commons Attribution 4.0 International License (http://creativecommons. org/licenses/by/4.0/), which permits use, sharing, adaptation, distribution and reproduction in any medium or format, as long as you give appropriate credit to the original author(s) and the source, provide a link to the Creative Commons license and indicate if changes were made.

The images or other third party material in this chapter are included in the chapter's Creative Commons license, unless indicated otherwise in a credit line to the material. If material is not included in the chapter's Creative Commons license and your intended use is not permitted by statutory regulation or exceeds the permitted use, you will need to obtain permission directly from the copyright holder. 